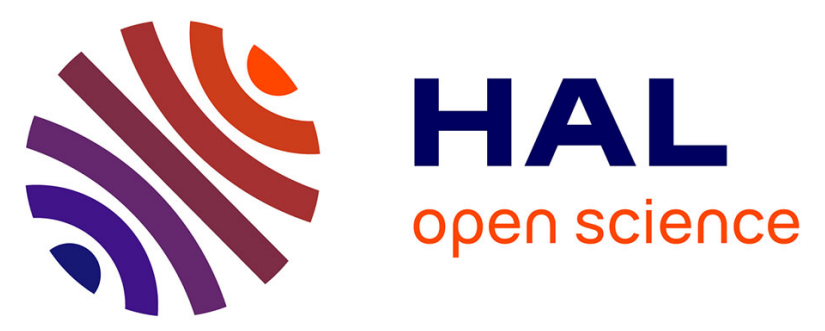

\title{
Nanoscience and nanotechnologies for biobased materials, packaging and food applications: New opportunities and concerns
}

\author{
William Dudefoi, Ana Villares, Stéphane Peyron, Céline Moreau, \\ Marie-Hélène Ropers, Nathalie Gontard, Bernard Cathala
}

\section{To cite this version:}

William Dudefoi, Ana Villares, Stéphane Peyron, Céline Moreau, Marie-Hélène Ropers, et al.. Nanoscience and nanotechnologies for biobased materials, packaging and food applications: New opportunities and concerns. Innovative Food Science \& Emerging Technologies / Innovative Food Science and Emerging Technologies, 2018, 46, pp.107-121. 10.1016/j.ifset.2017.09.007 . hal-01837525

\section{HAL Id: hal-01837525 \\ https://hal.science/hal-01837525}

Submitted on 27 May 2020

HAL is a multi-disciplinary open access archive for the deposit and dissemination of scientific research documents, whether they are published or not. The documents may come from teaching and research institutions in France or abroad, or from public or private research centers.
L'archive ouverte pluridisciplinaire HAL, est destinée au dépôt et à la diffusion de documents scientifiques de niveau recherche, publiés ou non, émanant des établissements d'enseignement et de recherche français ou étrangers, des laboratoires publics ou privés. 


\section{Accepted Manuscript}

Nanoscience and nanotechnologies for biobased materials, packaging and food applications: New opportunities and concerns

William Dudefoi, Ana Villares, Stéphane Peyron, Céline Moreau, Marie-Hélène Ropers, Nathalie Gontard, Bernard Cathala

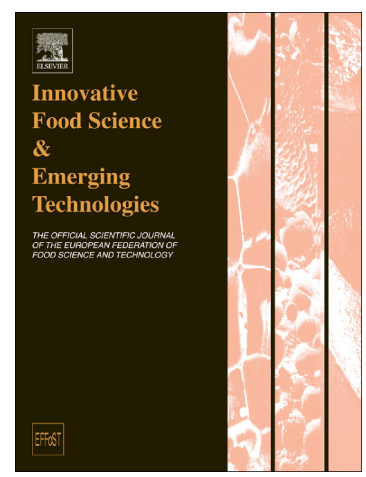

PII:

S1466-8564(17)30249-7

DOI: doi: $10.1016 /$ j.ifset.2017.09.007

Reference:

INNFOO 1845

To appear in:

Innovative Food Science and Emerging Technologies

Received date:

27 February 2017

Revised date:

1 July 2017

Accepted date:

13 September 2017

Please cite this article as: William Dudefoi, Ana Villares, Stéphane Peyron, Céline Moreau, Marie-Hélène Ropers, Nathalie Gontard, Bernard Cathala, Nanoscience and nanotechnologies for biobased materials, packaging and food applications: New opportunities and concerns, Innovative Food Science and Emerging Technologies (2017), doi: 10.1016/j.ifset.2017.09.007

This is a PDF file of an unedited manuscript that has been accepted for publication. As a service to our customers we are providing this early version of the manuscript. The manuscript will undergo copyediting, typesetting, and review of the resulting proof before it is published in its final form. Please note that during the production process errors may be discovered which could affect the content, and all legal disclaimers that apply to the journal pertain. 


\section{Nanoscience and nanotechnologies for biobased materials, packaging and food applications: new opportunities and concerns}

William Dudefoi ${ }^{2}$, Ana Villares², Stéphane Peyron ${ }^{1}$, Céline Moreau $^{2}$, Marie-Hélène Ropers ${ }^{2}$, Nathalie Gontard $^{1}$, Bernard Cathala ${ }^{2 *}$

*: corresponding author, Bernard.cathala@inra.fr

1: UMR IATE, CIRAD, INRA, Montpellier SupAgro, Université de Montpellier, 2 place Pierre Viala, 34060 Montpellier, France

2: INRA Unité BIA, Rue de la Géraudière, BP 71627, 44316 Nantes Cedex 3, France

Abstract: In the past decades, research into nanoscience and nanotechnologies has grown explosively and stimulated a large panel of scientific and technological fields. The boosting effect comes from either the reinvestigation of scientific fields by considering the nanoscale as a relevant level for improving our knowledge or from the extraordinary development of new tools that have democratized access to the nanoscale, such as AFM which is now a routine tool in most labs. This stimulating research has also reached the field of food science and biobased products. The INRA's Science for Food \& Bioproducts Engineering division ('CEPIA') has been engaged in this huge challenge, and selected results are presented here. 
Keywords: Adsorption, Biobased materials, Cellulose, Biopolymers, Interactions, Nanocellulose, Nanoparticles, TiO2, Food, Digestion, Food eco-packaging, Food packaging nanocomposite, Safety, Food contact materials

In the past decades, research into nanoscience and nanotechnologies has grown explosively and stimulated a large panel of scientific and technological fields. The boosting effect comes from either the reinvestigation of scientific fields by considering the nanoscale as a relevant level for improving our knowledge or from the extraordinary development of new tools that have democratized access to the nanoscale, such as AFM which is now a routine tool in most labs. This stimulating research has also reached the field of food science and biobased products. The INRA's Science for Food \& Bioproducts Engineering division ('CEPIA') has been engaged in this huge challenge, and selected results are presented here. Nanoscience and nanotechnologies involve working with manufacturing to characterize and manipulate materials of nanometer-scale size and can thus have impacts in many fields related to biomass production and transformation for food and non-food applications, from food production to biobased products. In this review, we illustrate the impact of nanoscience and nanotechnologies in three representative fields of applied research developed at INRA's Science for Food \& Bioproduct Engineering division. Part one gives examples of the use of biological elements (i.e. polymers or nanoparticles) to build biobased nanomaterials for a better understanding of the biological object. Specific properties of biological macromolecules are described, such as the ability to be specifically hydrolyzed or modified by enzymes, that can be used to engineer innovative materials. Part two covers engineered nanomaterials for food packaging. In the extensive field of nanoscience R\&D, food packaging is without a doubt the most active area, as there is better consumer acceptance and regulatory attention for such "out-of-food" applications than "inside" food applications. Wide variety of nanoparticles such as organic/mineral nanospheres, nanotubes or nanosheets is the key factor driving the development of novel engineered nanomaterials (ENM) for food packaging. These innovative ENMs aim to either enhance the functional properties of conventional packaging and/or provide innovative active and 'smart' functionalities, with 
very special expectations for sustainable bioplastics. Here we focus on overviewing the nanotechnologies used to design innovative and breakthrough functionalities in food packaging areas, and especially safety issues tied to migration from packaging into food.

Finally, part three deals with the nanoparticles present in food products. Since the discovery of nanoparticles in food, there has been a attempts to characterize them. The INRA's Science for Food and Bioproduct Engineering division contributed to this effort by analyzing the amount of $\mathrm{TiO}_{2}$ nanoparticles present in some confectioneries, the physicochemical properties of this additive, and the fate of the particles after consumption. Here we describe the steps leading to the identification of this food additive in the coating of sweets and the general properties of food-grade $\mathrm{TiO}_{2}$ in comparison to another source of titanium dioxide. We conclude by briefly explaining what happens to these particles once they have been ingested, including excretion, absorption and bioaccumulation.

\section{Nanostructured surfaces and thin films of plant cell wall biopolymers}

Nanostructured surfaces or thin films can be described as a chemically and morphologically-defined deposit of matters which in general present typical dimensions in thickness varying from one to a few hundred nanometers. Surfaces and thin films have long been a focus of research ever since they found applications in many industrial fields, but the advent of nanoscience and nanotechnology has sparked a surge in the number reports and research projects on nanostructured surfaces (Barth, Costantini et al. 2005). This renewed interest stems from the amazing effects that arise when size is reduced down to nanoscale in a controlled manner. All sorts of materials have been used to build nanostructured surfaces and thin films, from atoms (Knez, Niesch et al. 2007) to polymers (Decher 1997; Kontturi, Tammelin et al. 2006)and back to nanoparticles (Schuetz and Caruso 2002; Martin and Jean 2014). Among all the sources reported in literature, biological objects provide fascinating examples of nanoscale organization that can serve as inspiration to optimize uses of bioresources and engineer innovative materials. Plant cell wall is a three-dimensional network of chemically complex polymers composed of cellulose, hemicellulose, lignin and, to a lesser extent, proteins. These biopolymers represent one of the main sources of 
renewable materials that are raw components for both food and non-food applications. Plants cell walls thus offer amazing case studies of the importance of nanoscale in biological functions. For instance, the mechanical properties of wood are intimately related to cellulose microfibril orientation at nanometric scale (Salmen 2004). Sap transport and cavitation resistances are linked to nanoscale vessel architecture and the size of the torus present in the pits (Cochard 2006; Lens, Tixier et al. 2013). Nanostructured surfaces of biopolymers thus provide simple, dense and anisotropic systems that can be used as tunable models of the interface and surface to mimic naturally-existing materials and investigate both fundamental hypotheses of plant cell wall biology such enzymatic degradation processes (Josefsson, Henriksson et al. 2007; Ahola, Turon et al. 2008; Cerclier, Guyomard-Lack et al. 2013) or polymer interactions (Holmberg, Berg et al. 1997; Stiernstedt, Nordgren et al. 2006; Winter, Cerclier et al. 2010; Villares, Moreau et al. 2015). Nanostructured surfaces also serve to investigate complex industrial processes such as pulp production or paper coatings through a simplified approach. Model surfaces or thin films can then be studied with various powerful analytical tools offered by surface science that cannot be applied to real substrates such as plant cell wall or manufactured products. Nanostructured biopolymer surfaces and thin films are also functional materials per se, and the fine control of their architectures can afford amazing functional properties. For instance, thanks to their nanometric dimensions lower than the wavelength of light, nanostructured surfaces and thin films can display optical properties such antireflectivity or structural colors (Cathell and Schauer 2007; Cerclier, Guyomard-Lack et al. 2011; Azzam, Moreau et al. 2014; Azzam, Moreau et al. 2015). Finally, as biopolymers are biological molecules, they can be expected to possess characteristic features such as specific recognition, sensitivity to stimuli or susceptibility to enzymes. Enzymes can thus be used as modifying agents for patterning, or in reverse, biopolymer thin films can be used as simplified systems for studying enzyme action. Here we detail selected examples of recent progress made at the INRA's, Science and Process Engineering of Agricultural Products division in the fabrication, study and uses of biopolymer nanostructured surfaces and their interactions, with special focusing on the general method 
employed to fabricate biopolymer thin films and surfaces and their use to (i) study enzymatic degradation processes, (ii) create micro/nanostructuration surfaces and (iii) detect enzymatic activity.

\section{Preparation of biobased nanostructured surfaces or thin films}

The preparation of nanostructured surfaces of biopolymers generally uses the three core methods employed for polymer surface or thin film fabrication. The first is the so-called "Langmuir-Blodgett" method-named from the inventors-which is a long-standing well-established method for the preparation of thin films/surfaces (Langmuir 1920; Blodgett 1934; Blodgett 1935). The first step consists in dissolving the polymer in a suitable solvent then spreading the solution on the surface of a nonsolvent liquid (usually water). In the second step, after evaporating the dissolving solvent and compressing the molecules on the surface, the film is transferred from the liquid/air interface onto a solid surface by moving a solid substrate upward or downward through the surface while keeping the surface pressure constant by moving the barrier in an appropriate manner. This approach has been applied for instance in cellulose nanocrystal (CNC) thin film fabrication (Habibi, Foulon et al. 2007) where negatively-charged, rod-like CNCs formed stable layers at the air-water interface in the presence of a cationic amphiphilic molecule. The layers formed can be efficiently transferred onto silicon wafers to afford well-structured surfaces with low roughness.

The second widespread method for preparing polymer surfaces or thin films is the spin-coating process. In this method, a polymer solution is deposited on a solid substrate and the solvent is removed with the aid of high-speed spinning to afford uniform polymer films. Film properties can easily be tailored by adjusting experimental parameters such as spin velocity, acceleration or solution viscosity. This method has been applied for instance to prepare cellulose model surfaces from both dissolved cellulose or dispersed nanocellulose (Kontturi, Thune et al. 2005; Cranston and Gray 2006; Kontturi, Johansson et al. 2007; Winter, Cerclier et al. 2010).

The latest popular method is layer-by-layer (LbL) self-assembly originally developed for the preparation of polymer-based nanostructured surfaces (Decher 1997). It consists in the alternate deposition of polymers or particles presenting attractive interactions. Electrostatically-driven polymer assemblies, 
including synthetic and/or biopolymers, are the most frequent assemblies found in the LbL literature, but there are also reports of a buildup process through non-electrostatic interactions (Picart, Lavalle et al. 2001; Boddohi, Killingsworth et al. 2008; Olszewska, Kontturi et al. 2013). Using this buildup strategy, the elaboration of multilayered structures based on nanocellulose such as CNC or cellulose nanofibrils (CNF) has also been investigated, and changes of processing parameters can be tuned to obtain a large variety of structural and physical properties (Valentin, Cerclier et al. 2010; Moreau, Beury et al. 2012; Martin and Jean 2014; Decher and Schlenoff 2012; Borges and Mano 2014; Jean 2014; Richardson, Björnmalm et al. 2015; Moreau, Villares et al. 2016).

In the context of plant cell wall biopolymers, the fabrication of bioinspired assemblies that can mimic interactions and phenomena occurring in plant cell walls is a powerful approach for gaining insight into cell wall organization. Electrostatic-based LbL has been successfully applied for the elaboration of extensin/pectin thin films in order to investigate the force and quality of interactions between the two polymers (Valentin, Cerclier et al. 2010). Recently, Dammak et al. (Dammak, Moreau et al. 2013) also fabricated multilayered thin films based on electrostatic interactions from the alternate deposition of $\mathrm{CNC}$ and cationic xylan $(\mathrm{CX})$ solutions that were synthesized from oat spelt xylans after reaction with epoxypropyltrimethylammonium chloride (Schwikal, Heinze et al. 2011) in order to have minimum cationic charge for adsorption to the CNC layer.

Biomimetic cellulose nanocrystals/xyloglucan assemblies have also been prepared by the LbL method (Jean, Heux et al. 2008; Winter, Cerclier et al. 2010). Multilayers are stabilized by the interaction between cellulose and xyloglucan, which is assumed to be mediated by hydrogen bonding, hydrophobic interactions and van der Waals dispersion forces, and deposition is achieved for up to eight bilayers. Construction of the films can be only achieved when xyloglucan (XG) concentration is low enough to allow two cellulose nanocrystal surfaces to crosslink. At higher concentrations, the connection by one chain of two surfaces cannot be achieved. The upper phase is removed during the washout, demonstrating the dual adhesive and antiadhesive capacities of XG that have been investigated via in vivo and in vitro studies (Stiernstedt, Nordgren et al. 2006; Winter, Cerclier et al. 2010; Cosgrove 2014). 


\section{Enzymatic patterning of biobased surfaces}

As biological substances, biopolymers display unique properties that cannot be achieved by synthetic polymers. Over the course of evolution, nature has managed to develop enzymes that cleave or form chemical linkages with exquisite specificity. Specific hydrolysis of biopolymers with appropriate enzymes can be used for nano or micro-structuration of biopolymer thin films or surfaces. The ability to pattern bio-surfaces at different length scales is important for the development of many applications, from molecular and cellular biosensors to biomaterials, optics and electronics. Among the many methods for nano- and micro-patterning thin films, microcontact printing $(\mu \mathrm{CP})$ transfers patterns by using soft elastomeric stamps, generally poly-(dimethylsiloxane) (PDMS) stamps. $\mu \mathrm{CP}$ can also be used for enzymatic modification of biopolymer films thanks to highly selectively enzymatic hydrolytic activities. A versatile patterning method for biopolymer thin films can be achieved by $\mu \mathrm{CP}$ using enzymatic reaction as pattern formation (Guyomard-Lack, Delorme et al. 2011; Guyomard-Lack, Moreau et al. 2012). For this purpose, covalent trypsin attachment was successfully performed on patterned PDMS microstamps consisting of $1 \mathrm{~mm}$ lines spaced $3 \mathrm{~mm}$ apart. The contact with poly-L-lysine (PLL), the substrate of trypsin, results in enzymatic digestion. After the enzymatic degradation of PLL and removal of the degradation products, very well-defined patterning was revealed over a large area The process offers very high lateral resolution at (micro)-nanoscale and selectivity (Fig. 1A). AFM topographic images of patterned film show excellent long-range periodicity of lines corresponding to PLL lines or degraded PLL lines (Fig. 1B). 

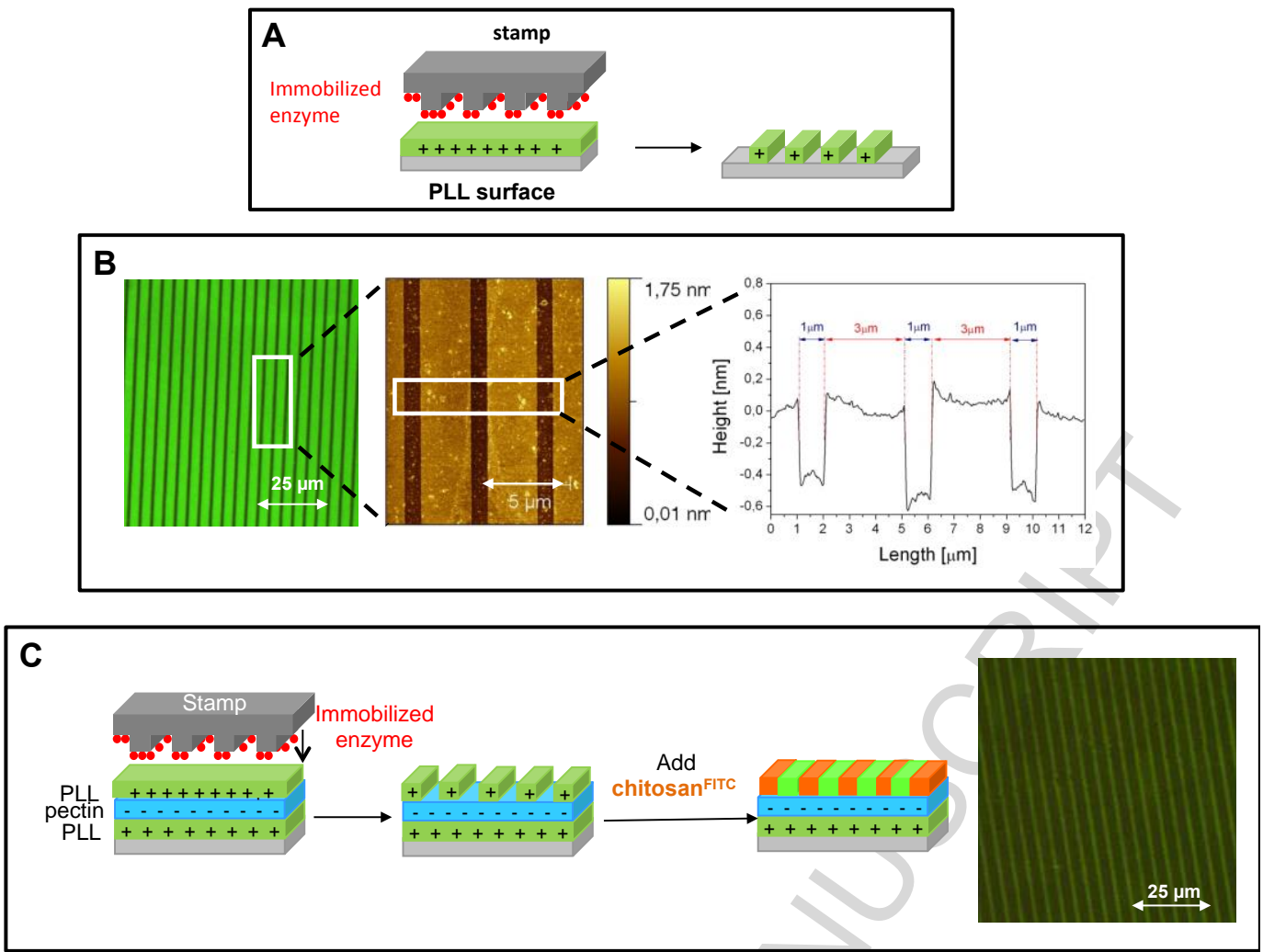

Fig. 1.

A Schematic representation of the enzymatic microlithography process with (B) the resulting AFM topographic image of the patterned PLL surface (scale: $5 \mu \mathrm{m}$ ) and line profile of the corresponding AFM image. C Patterning process of multilayered thin films composed of pectin and PLL. When the stamp is applied on the film, only the top layer is patterned, which allows the formation of alternate positive and negative lines highlighted by further site-selective adsorption of cationic polymer.

This enzymatic patterning by trypsin was also applied to PLL/pectin multilayer assemblies for selective degradation of the top layer. Indeed, since only the top layer composed of PLL was the substrate of the trypsin, the underlying layer composed of pectin was unaffected by enzymatic degradation. Negativelycharged surface arising from pectin were exposed on the surface, thus inducing different topographic and chemical properties of the film surface (Guyomard-Lack, Delorme et al. 2011). This strategy allows the site-selective adsorption of biopolymers and pectin beads, for instance (Fig. 1C) (Guyomard-Lack, Delorme et al. 2011; Guyomard-Lack, Moreau et al. 2012). Kargl et al (Kargl, Mohan et al. 2013) later used an enzymatic patterning strategy called micromolding in capillaries (MIMIC) to create surface 
patterning from pure and regenerated (trimethylsilyl cellulose, TMSC) cellulose. By applying a patterned mask (microchannels $=40-100 \mu \mathrm{m}$ width spaced at $50 \mu \mathrm{m}$ ) onto the TMSC surface and using the common regeneration procedure ( $\mathrm{HCl}$ vapors), regeneration of TMSC to cellulose is achieved in the exposed areas only. Furthermore, filling stamp capillaries with cellulase solution on these patterned films allows selective degradation of pure cellulose thin films, whereas pure TMSC cannot be digested. These techniques make it possible to create biopolymer film patterns with specific surface topography and chemistry (e.g. hydrophilic/hydrophobic domains, crystalline/amorphous regions), and to selectively functionalize the surfaces through available reactive groups of biopolymers.

\section{Thin films as biomimetic model and biomass degradation model surfaces}

The literature reports a number of approaches to investigate cell wall polymer organization and interactions using physical, spectroscopic and biochemical techniques. These approaches on living systems are often limited by the complexity of the cell wall on top of experimental limitations (typically sample size or biological variability). Simplified systems such as re-constructed nanostructured thin films or surfaces can thus be helpful in identifying the role of individual cell wall components and physicalchemical processes. For instance, interlinked phenomena can be disconnected by the specific addition or removal of one component in in vitro experiments, which also opens access to very dense systems since the surface concentrations, even in hydrated films, are in general far higher than those reached in solutions. The primary cell wall of dicotyledonous plants is composed of a load-bearing network of cellulose fibrils covered and interconnected by hemicellulosic polysaccharides. Hemicelluloses provide the strong yet flexible properties by crosslinking cellulose microfibrils and preventing them from selfassociation post-biosynthesis. Studies on cell wall arrangement have given rise to several theories on cellulose/XG association. The original hypotheses pointing to a macromolecular matrix made of covalently linked domains of XG, pectins and structural proteins (Keegstra, Talmadge et al. 1973) gave way to the tethered network model which postulated the coating of cellulose by XG as the key structural determinant of plant growth (Carpita and Gibeaut 1993). However, recent studies indicate that only a small proportion of the cellulose surface is coated by XG. Hence, certain cellulose microfibrils would be 
in contact, and XG would act as a one-molecule-thick adhesive between them. Therefore, mechanical properties and wall extension would be controlled at limited regions of close contact between cellulose microfibrils, mediated by the XG chains (Park and Cosgrove 2012).

In an attempt to gain a deeper understanding of the adsorption of XG onto the cellulose surface, we developed a kinetic model that gives more insight into the arrangement of polymer chains on the cellulose surface (Villares, Moreau et al. 2015). The model takes into account two contributions to the adsorption process: (i) at low XG concentration or short adsorption time, every XG molecule reaching the uncovered CNC surface is directly adsorbed and has time to rearrange before new molecules arrive, likely as a monolayer or pancake conformation; (ii) when a certain coverage is reached, the preformed layer prevents further molecules adsorbing on the surface by steric hindrance and the unavailability of binding sites. The overall adsorption process can therefore be described as the contribution of XG adsorption onto the uncovered CNC surface and the contribution of adsorption onto pre-covered CNC surfaces after XG rearrangement (Wågberg, Ödberg et al. 1988; Couture and Vandeven 1991; De Witt and Van de Ven 1992) (Fig. 2).

We prepared model cellulose surfaces using spin-coating to deposit one layer of CNC onto gold-coated quartz crystals, and then monitored XG adsorption in situ by quartz crystal microbalance with dissipation (QCM-D). XG adsorption at different concentrations did not result in the same frequency decrease at the end of the adsorption experiment, which means that increasing XG concentration resulted in higher amounts of XG adsorbed. Kinetic studies evidenced the presence of two adsorption regimes as a function of XG concentration. For low XG concentrations, the adsorption after rearrangement was faster than the adsorption onto uncovered CNC surfaces, indicating that XG chains adsorb on CNC in a rather flat conformation with a high percentage of trains in close contact with the cellulose surface. Conversely, for higher XG concentrations, the kinetic constant related to the conformational rearrangement decreases, indicating that XG molecules have no time to laterally rearrange before new XG molecules adsorb, and the XG loops and tails do not have time to laterally rearrange to a flat conformation before new XG molecules adsorb (Villares, Moreau et al. 2015). 


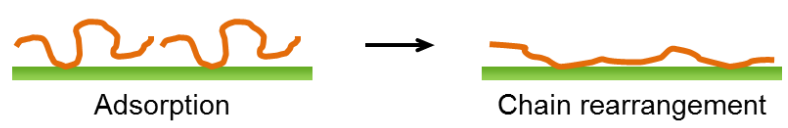

b High XG concentration:

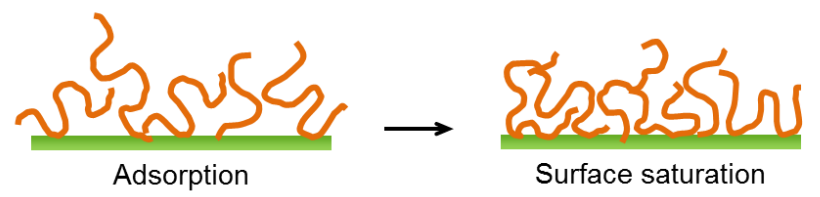

Fig. 2.

Schematic description of XG adsorption onto CNC surfaces at very diluted (a) and more concentrated (b) $X G$ regimes.

In fact, the two CNC/XG complexes fabricated from low and high XG concentrations, respectively, show different enzymatic accessibility. We previously demonstrated that CNC/XG assemblies prepared from concentrated solutions experienced a higher mass loss upon incubation with a XG-specific endoglucanase than CNC/XG assemblies fabricated at low XG concentration (Dammak, Quemener et al. 2015). The different arrangement of XG chains at the cellulose surface was shown to be crucial for certain applications, such as the stabilization of colloidal suspensions. Colloidal stability hinges on avoiding aggregation and flocculation. When bacterial cellulose is coated with XG at low concentration, XG chains can cross-link cellulose nanocrystals and therefore promote association, which results in aggregation and consequently low colloidal stability. In contrast, for the CNC/XG assemblies prepared from XG at high concentration, the loops and tails formed by the XG chains at the cellulose surface prevent aggregation by steric stabilization (Winter, Cerclier et al. 2010).

We have also studied the impact of molar mass on adsorption behavior (Villares, Bizot et al. 2016) and demonstrated that a decrease in XG molar mass from $10.28 \cdot 10^{5} \mathrm{~g} \cdot \mathrm{mol}^{-1}$ to $1.04 \cdot 10^{5} \mathrm{~g} \cdot \mathrm{mol}^{-1}$ has impacts on XG conformation on the CNC surface. High-molar-mass XG $\left(10.28 \cdot 10^{5} \mathrm{~g} \cdot \mathrm{mol}^{-1}\right)$ formed loops and tails on CNCs whereas low-molar-mass XG $\left(1.04 \cdot 10^{5} \mathrm{~g} \cdot \mathrm{mol}^{-1}\right)$ adsorbed in an extended conformation forming trains on the cellulose surface. The presence of different conformations depending on molar mass of XG 
was confirmed by the greater accessibility of high-molar-mass XG loops compared to low-molar-mass XG trains upon hydrolysis of CNC-XG-CNC assemblies by an XG-specific endoglucanase.

\section{Enzymatic detection}

Plant biomass transformation processes to produce monosaccharides and oligosaccharides need a far better enzymatic treatment to degrade lignocellulosic materials. However, the cellulose microfibrils in plant cell walls are encrusted in lignin and hemicelluloses in a complex architecture that, together with the crystallinity of cellulose, makes cellulosic biomass recalcitrant to hydrolysis to fermentable sugars. Enzyme cocktails need to be optimized and new enzymes discovered, so a critically important challenge is to develop easy-to-use, sensitive and rapid screening tests applicable to a wide range of hydrolytic enzymes (Arantes, Gourlay et al. 2014; Lee, Hamid et al. 2014; Alvarez, Reyes-Sosa et al. 2016). Traditional methods to determine specific enzyme activity are based on detecting the reducing sugars formed during biopolymer hydrolysis in solution (Somogyi 1937; Nelson 1944; Somogyi 1945). Assemblies of biopolymers onto a solid surface at nanoscale can prove valuable model systems for investigating enzyme hydrolysis. By controlling the deposition conditions as well as the polymer solution characteristics, it becomes possible to prepare thin films of appropriate thickness, composition and porosity, and biopolymer thin films with the appropriate layer architecture are able to produce strong interference colours. Indeed, when film/layer architecture is tuned to appropriate values of thickness and refractive index, there is an interference that occurs between light reflected from the air-film interface and from the film-substrate interface (Fig. 3) (Hiller, Medel et al. 2002).

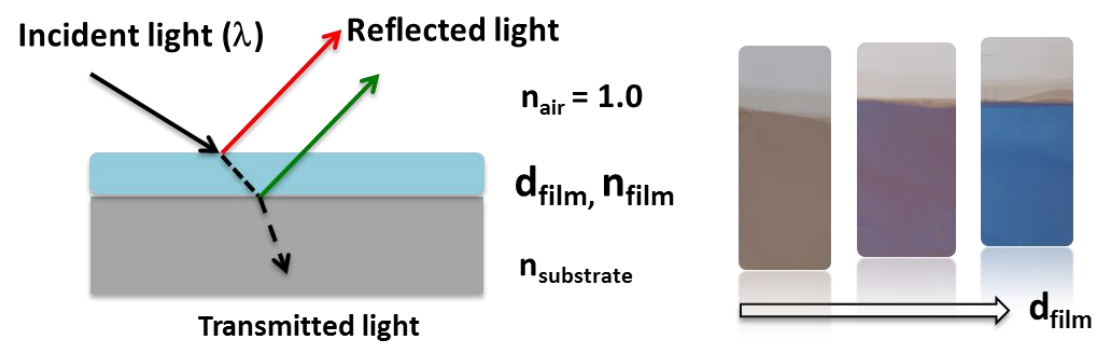

Fig. 3. 
(left) Schematic representation of the optical interference phenomenon between the air/film and film/substrate interfaces. (right) Example of the resulting colored films based on alternate deposition of poly(allylamine hydrochloride) and CNC layers as film thickness increases.

These structurally colored films were achieved from spin-coated or dip-coated polyelectrolyte/CNC multilayer films (Cranston and Gray 2006; Podsiadlo, Sui et al. 2007; Jean, Dubreuil et al. 2008; Moreau, Beury et al. 2012). Alginate films fabricated by spin-coating were then exposed to aerosolized $\mathrm{CaCl}_{2}$ solution to enable layer crosslinking (Cathell and Schauer 2007). All these works showed that homogenous film surfaces of various nanometer-scale thicknesses can be produced with a wide variety of reflected colors simply by varying deposition-procedure parameters (e.g. spin-coating velocity or adsorption time) and/or biopolymer characteristics (e.g. concentration, nature, ionic strength) (Decher and Schlenoff 2012; Borges and Mano 2014; Jean 2014; Richardson, Björnmalm et al. 2015; Moreau, Villares et al. 2016). We recently showed in fully biosourced (CNC/XG) films that CNC layer structure can be tuned by increasing CNC concentration from 3 to 5 g. $\mathrm{L}^{-1}$ to deposit a single or double layer of CNC (Jean, Heux et al. 2009; Winter, Cerclier et al. 2010; Guyomard-Lack, Cerclier et al. 2012). Film surface color can be changed from brown to blue by controlling film architecture, composition and thickness. Biopolymer films displaying this remarkable optical property served to design highly sensitive detectors for biomass-hydrolyzing enzymes (Cerclier, Guyomard-Lack et al. 2011; Dammak, Moreau et al. 2013). Indeed, when films are in contact with specific enzymes able to hydrolyze biopolymers, there is a change of film color due to the thickness decrease of the degraded layer. Fig. 3 illustrates the principle of this concept from (CNC/XG) film with a blue color. A droplet of cellulose solution is deposited onto the film surface and after $10 \mathrm{~min}$ and a rinsing step with water (Fig. 4A), various color changes are directly observed as function of the concentration of the enzyme solution (Fig. 4B). Different colored spots appear, indicating a decrease in thickness of the biopolymer layers as a function of enzyme concentration. In Fig. 3B, the lowest concentration of enzyme detected is $10 \mu \mathrm{g} \mathrm{ml}^{-1}$. In the same way, films containing six bilayers of CNC and cationic xylan show highly sensitive and specific responses to 
xylanase at different concentrations (Dammak, Moreau et al. 2013). This new assay for enzymatic activity detection based on color change of nanostructured biopolymer films is a simple yet highly sensitive method compared to commonly used methods. It offers new opportunities to detect a broad range of enzymes specific to biomass polymers.
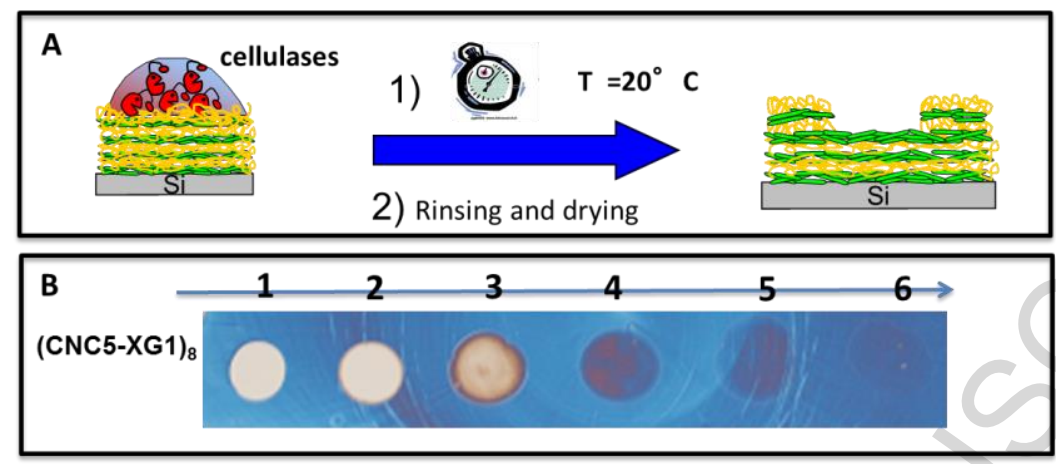

Fig. 4.

(A) Schematic representation of an enzyme detection test consisting of depositing an enzyme droplet $(\sim 2 \mu \mathrm{L})$ onto a multilayered film, and then, after a deposition time at $20^{\circ} \mathrm{C}$, the film is rinsed and dried under a nitrogen stream. (B) Multilayer film of (CNC/XG) at 8 bilayers originally displaying a blue color and spots corresponding to Cellulyve enzyme degradation of the film at an enzyme concentration of (1) $5000 \mu \mathrm{g} / \mathrm{mL}$, (2) $50 \mu \mathrm{g} / \mathrm{mL}^{-1}$, (3) $25 \mu \mathrm{g} / \mathrm{mL}^{-1}$, (4) $20 \mu \mathrm{g} / \mathrm{mL}^{-1}$, (5) $15 \mu \mathrm{g} / \mathrm{mL}^{-1}$ and (6) $10 \mu \mathrm{g} / \mathrm{mL}^{-1}$.

\section{Conclusion}

Progress in creating biobased surfaces and thin films has produced useful tools for obtaining functional and/or chemical information from plant cell wall biopolymers. The ability of such biological molecules to naturally self-organize in nature makes it possible to fabricate many novel nanoscale materials inspired from specific natural properties and chemical complementarity.

The nanostructuration of biopolymer assemblies is thus a never-ending source of inspiration for the elaboration of biomimetic models of plant cell walls but also for the elaboration of new materials with amazing properties. Interactions occurring between biopolymers and affecting self-assembly and/or interfacial properties are thus of great interest for engineering materials and for efficient transformation 
of bioresources. The enzymatic susceptibility of such biological surfaces/thin films successfully illustrates one of the efficient advantages of these new nanostructured materials.

\section{Nanocomposite materials for food packaging applications: improving functional properties and safety concern}

In the extensive field of nanoscience R\&D, food packaging is without a doubt one of the most promising and advanced R\&D areas, posting a compound annual growth rate of $12.7 \%$ for commercial applications (Bumbudsanpharoke and Ko 2015). The development of engineered nanomaterials (ENM) for food packaging applications aims either to enhance the mechanical and barrier properties of conventional or biobased packaging materials and/or provide innovative active and intelligent functionalities. As defined in the food contact material framework regulation 1935/2004, active and intelligent packaging deliberately incorporates active or intelligent components intended to release or absorb substances into, onto or from the packaged food or its surrounding environment, or to provide the intended information, with their conditions of use. A large portfolio of nanoparticles spanning organic/mineral nanospheres, nanotubes and nanosheets is being used to drive the development of such innovative packaging materials. Indeed, consumer acceptance and regulatory attention are easier to manage with such "outof-food" applications than "inside" food applications (Siegrist, Stampfli et al. 2008; Duncan 2011). Active ENM packaging is based on introducing substances inside the material matrix, or attached to the surface or trapped in between different layers, to maintain the quality and safety and extend the shelf life of the food. Oxygen absorber is one such substance. These innovative packagings have attracted much attention in the food industry as a way to replace conventional food preservation systems (Cho, Lee et al. 2011) in which levels of additives and physical-chemical treatments can lead to adverse effects that are avoidable with the use of efficient active material (Kanmani and Rhim 2014). Nanotechnology provides more efficient activity of the active substance at lower concentration, but also facilitates their 
incorporation into the packaging materials without detrimental impact in other packaging properties such as transparency, mechanical performance and barrier performance.

By providing accurate and easy-to-read information on food safety and quality, a new generation of intelligent ENM packaging materials has a key role to play in limiting/avoiding the safety and waste issues resulting from the margin of safety and misunderstanding of conventional food date labels. The unique optical, chemical, biochemical and electrical properties of nanoscale particles offer breakthrough foundations to develop cost-efficient 'smart' labels for food packaging applications.

Nanotechnology-based non-invasive sensors have radically changed the speed and accuracy of smallmolecule detection. Nanotechnologies can be easily embedded into the packaging material itself or into a label or a coating, to add an intelligent function to food packaging (Bowles and Lu 2014). These socalled "intelligent packagings" are able to provide users with appropriate in-time information on the quality and safety of the food, either indirectly by monitoring storage conditions such as time-

temperature history, or directly by monitoring the presence of food degradation markers. These indirect or direct indicators of food quality and safety are able to integrate multiple gas and volatile sensors useable on flexible substrate such as packaging materials. Recent special attention to wireless sensors could potentially lay the foundation for the truly convergent wireless sensor ad hoc networks of the future (Gontard, Peyron et al. 2017).

Even though nanotechnologies are increasingly gaining ground worldwide in the food packaging sector, no regulations on nanotechnology applications have been yet established in Europe or elsewhere. Food packaging nanotechnologies are thus presumed to be covered by existing legislation. Consequently, and like any other food-contact material (FCM), nanomaterials must comply with the provisions of the European framework regulation (EC) 1935/2004 (European Commission 2004) that defines general requirements to ensure that the substances migrating from the material into the food do not endanger human health nor deteriorate the organoleptic characteristics of food in an unacceptable way. In addition to these requirements which define the general principle of inertia, the framework regulation 
reports a list of 17 groups of materials and articles which may be covered by specific measures and which have not yet been harmonized at EU level. To date, only four FCMs (i.e. plastics, ceramics, regenerated cellulose film, and active and intelligent materials) are subject to such 'specific measures', and nanomaterials are not included in the list.

From a regulatory point of view, even the actual definition of "nanomaterial" still caused controversy. In the United States, the Food and Drug Administration (FDA) has not established regulatory definitions of "nanomaterial", "nanotechnology", "nanoscale" or other related terms, admitting that these terms are commonly used in relation to the engineering (i.e. deliberate manipulation, manufacture or selection) of materials that have at least one dimension in a size range running from approximately 1 nanometre $(\mathrm{nm})$ up to $100 \mathrm{~nm}$ (U.S. Food and Drug Administration 2014). The FDA considers that evaluations of safety, effectiveness, public health impact, or regulatory status of nanotechnology products should consider any unique properties and behaviours that the application of nanotechnology may impart. The various draft guidance documents the agency has issued to date on the topic reiterate the FDA's view that nanotechnology represents an "evolving state of the science," and that a single definition of nanotechnology and its related terms is inappropriate for regulatory purposes until more can be learned about the interaction of nanomaterials with biological systems.

The European Commission defines a nanomaterial as "a natural, incidental, or manufactured material containing particles, in an unbound state or as an aggregate and where, for $50 \%$ or more of the particles in the number size distribution, one or more external dimensions is in the size range $1 \mathrm{~nm}-100 \mathrm{~nm}$ " (European Union Executive 2011). In fact, we know little about the risk potentially linked to the polymer nanocomposites (PNC) used as FCM, and the strategic line of the European Food Safety Authority (EFSA) is based on a suitable risk assessment approach taking into account the "specific properties of the engineered nanomaterials in addition to those common to the equivalent non-nanoforms". The EU had already edited statutory texts in this direction along with technical guidance mentioning nanomaterials. In particular, the EU Plastics Regulation (EC) 10/2011 (European Commission 2011) meeting the terms of EC Regulation 450/2009 on active and intelligent materials and articles specifically states that new 
technologies that engineer substances in particle sizes that exhibit chemical and physical properties significantly diverging from those at a larger scale-nanoparticles included-should be risk-assessed on a case-by-case basis until more is known about the novel technology. On this basis and taking into account the lack of knowledge about their potential toxicity (oral exposure to engineered nanomaterials hasg received less attention than the dermal or inhalation pathways), the concept of functional barrier used to prevent migration of contaminants, which are not evaluated by health authorities, cannot be applied in the specific case of PNC packaging including nano-dimensional substances. This statement notably differentiates nanoform substances from non-nanoform susbstances which are authorized for use behind a functional barrier, provided that they fulfil certain criteria and their migration remains below a given detection limit.

It is important to point out that, in the case of food packaging applications, the risk assessment related to ENM goes beyond the nanometric paradigm to encompass two distinct issues:

1) the migration of the nanoparticles themselves or their constitutive elements

2) the impact of nanoparticle addition on the migration of other contaminants (i.e. monomers, additives or processing aids) which can potentially demonstrate toxicity.

The comprehensive evaluation of any PNC's suitability for contact with food products must necessarily include these two investigations.

\section{Migration of nanoparticles and exposure assessment}

Considering the first point, and in absence of any harmonized procedure, the difficulty of assessing the release of ENMs from packaging into a complex food matrix is the key challenge for controlling human exposure. Until more data are available and the assessment becomes standardized, the case-by-case approach will fatally involve a disparity of criteria and a high degree of uncertainty. However, new analytical methods and equipment are yet now to measure/detect minute fractions of migrating inorganic nanoparticles (Duncan 2011) .Lots of investigations have been conducted on nano-silver which is widely incorporated into a range of commercial active packagings due to its recognized antimicrobial properties (Duncan 2011). The net result of the work effort converges on the common finding that silver 
nanoparticles are evidenced to migrate but with migration values that do not exceed the European specific migration limit (SPL) of $0.05 \mathrm{mg} / \mathrm{kg}$ of food (European Food Safety (Authority 2005). However, the fact that nanoparticles generally dissociate quickly to ionic form for which oral genotoxicity data and carcinogenic potential are still missing (European Food Safety (Authority 2016) leads to apply the precautionary principle and a case-by-case hazard assessment. In addition, PNC production pathway (incorporation/coating), initial concentration, nature of the food and contact conditions (time/temperature) all impact the extent of nano-silver migration (Huang, Chen et al. 2011; Song, Li et al. 2011; Echegoyen and Nerín 2013; von Goetz, Fabricius et al. 2013; Bott, Strömer et al. 2014; Cushen, Kerry et al. 2014; Cushen, Kerry et al. 2014; Jokar and Abdul Rahman 2014; Artiaga, Ramos et al. 2015). Among nanomaterials developed for food packaging applications, nanoclay was the first to emerge to the market for the purpose of improving the barrier properties and mechanical performance of plastic polymers or reducing the water-sensitivity of biosourced materials. From a purely theoretical approach, the migration of montmorillonite (MMT) from common packaging materials could be considered negligible, given its slow rate of transfer due to its larger size than other spherical nanomaterials which have a radius of the order of 1 to $4 \mathrm{~nm}$, such as nanoparticles of silver, iron, zinc or titanium (Simon, Chaudhry et al. 2008; Bott, Störmer et al. 2014). Meanwhile, a number of experimental investigations have demonstrated MMT release by measuring the migration of elemental components (most commonly Si) from materials including 3 to $5 \%$ (w/w) of nanoclays (Chaudhry, Castle et al. 2008; Schmidt, Katiyar et al. 2011; Farhoodi, Mousavi et al. 2014; Maisanaba, Pichardo et al. 2014). The migration values measured from PNC including MMT in the different food simulants proved to be very low and did not generally exceed the concentrations typically found in foods. In this respect, consumer exposure and subsequent safety issues as a result of nanoclay incorporation into PNC was considered minimal, even though recent work demonstrated the migration of nanoform MMT from commercial packaging (Echegoyen and Nerín 2013). The transport mechanisms of MMT remain an open question, considering that the occurrence of nanoparticles in food could result distinctly from the release of the whole particles or from the post-migration assembly of ionic forms. In addition to nature of the food 
(solid/liquid, fatty/aqueous/acid, etc.) and contact conditions (time, temperature), the emergence of new processing technologies such as high-pressure, pulsed electric fields, cold plasma and advanced heating can also impact the potential release of MMT (or its constitutive elements). The effect of a highpressure treatment on food/packaging interactions was investigated with a particular focus on the intreatment and subsequent in-storage behavior of MMT (Mauricio-Iglesias, Peyron et al. 2010). The study performed on wheat gluten-based films including 5\% MMT submitted to high-pressure (HP) sterilization treatment (Fig. 5) demonstrated a significant increase of silicon migration from treated samples compared to wheat-gluten films submitted to conventional thermal treatment.

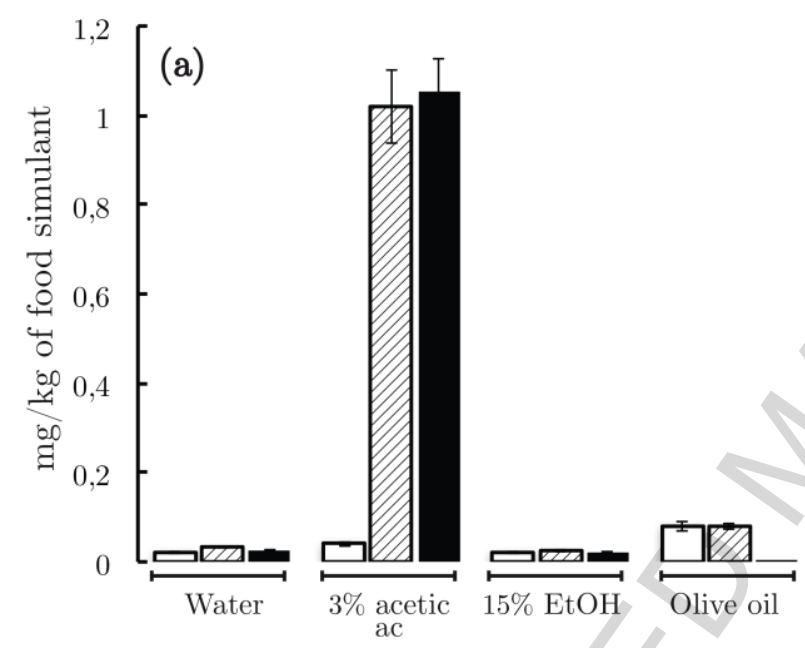

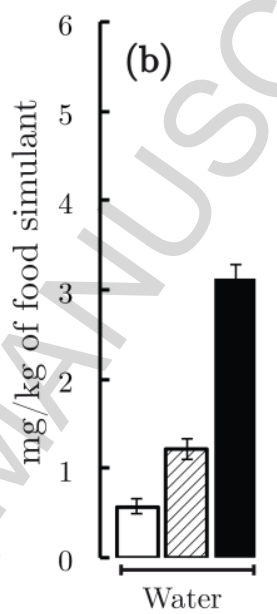

Water

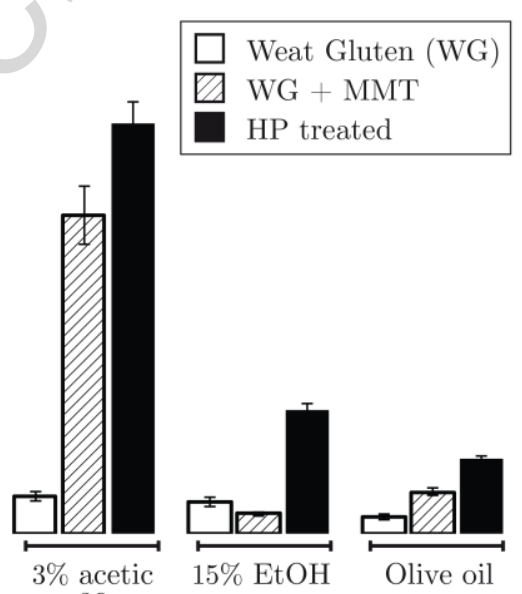

Fig. 5.

Concentration of aluminium (a) and silicon (b) in food simulant after HP/LT treatment $\left(800 \mathrm{MPa}, 40^{\circ} \mathrm{C}\right.$ ) or control treatment $\left(0.1 \mathrm{MPa}, 40^{\circ} \mathrm{C}\right)$ compared to $\mathrm{MMT}$-free film, and subsequent 10-day storage at $40^{\circ} \mathrm{C}$.

Note that the respective migrations of aluminium and silicon are not in accordance, which makes it difficult to ascertain which is the most accurate marker for MMT and demonstrate that the nanoparticle would be released after a potential HP-treatment-induced modification of its structure. The question "how do ENM migrate?" is far from irrelevant, since it is well established that their toxicity depends on a large number of factors including their structure, surface area, particle number, charge, chemistry, size and size distribution, aggregation state, shape and elemental composition (Oberdörster, Maynard et al. 2005; Handy and Shaw 2007). Consequently, the potential modifications of structure with HP treatments 
confirms the necessity of a thorough assessment of migration together with toxicological analysis whenever nanocomposite may be used in new food processing technologies.

\section{Impact of ENM incorporation on the inertia of food-contact packaging}

As mentioned above, the safety assessment of PNC in terms of human exposure cannot be restricted to the a study of ENM migration alone. The influence of ENM on the inertia of the nanocomposite packaging material remains a question given very little attention, despite being a key issue dictating the suitability of packaging to be in contact with food. Regulation (EC) 10/2011 (European Commission 2011), sets the requirement of inertia for the plastic material as (1) an overall migration limit (to $60 \mathrm{mg} \mathrm{kg}^{-1}$ of food), i.e. the total mass released by the packaging material during a migration test, and (2) a specific migration limit determined on the basis of toxicological data on every substance authorized for use in the manufacture of plastic materials (monomers, process aids and additives such as plasticizers, antioxidants, light stabilizers, etc.).

In the case of homogeneous material (considered as a continuous medium), migration phenomena fit well-established physical laws and can be described by diffusion models, most often based on Fick's second law. In this respect, the EU regulation authorizes the recognized diffusion models based on experimental data to determine overestimated migration levels, thereby avoiding expensive and timeconsuming experiments. This strategy is not easy to transpose to the specific case of NPC which can be considered a heterogeneous medium including impermeable particles and which present transport properties involving more complex physical laws. While the diffusion coefficient of a substance migrating in polymer blends is mainly influenced by it molecular characteristics (molar volume, shape and polarity) and the mobility of the polymeric chains (itself related to temperature, crystallinity of material, chain length and orientation, and other factors), diffusion in NPC is related to two additional factors, i.e. (1) the tortuosity of the diffusion path generated by the obstruction effect of the nanoparticles and (2) the possible interactions (sorption/adsorption) of the diffusing substance with the ENM. Furthermore, it is well established that nanometer-scale inorganic particles could induce a partial hydrolytic degradation and impact the degree of crystallization of polymeric materials by acting as a nucleating agent 
(Alexandre and Dubois 2000). The inclusion of nanoparticles could therefore indirectly influence the diffusion of low-molecular-weight molecules by modifying the movement of the polymeric chains that constitute the continuous matrix.

This last issue was addressed on polylactate-based nanocomposite including MMT (Cloisite 20). FT-IR analysis of the PNC was used to follow the structural properties of the polymer during film contact with five different food-simulating liquids (distilled water, 10\% ethanol, 3\% acetic acid, 95\% ethanol, and isooctane). This investigation evidenced that inclusion of MMT in a polylactate matrix induced the hydrolytic degradation of the polymer chains resulting in a released of lactic acid and lactide concomitantly with a decrease in polymer molecular weight. These structural modifications are not without effect on the inertia of the material, since overall migration proved to be significantly increased by the presence of MMT (Fig. 6)

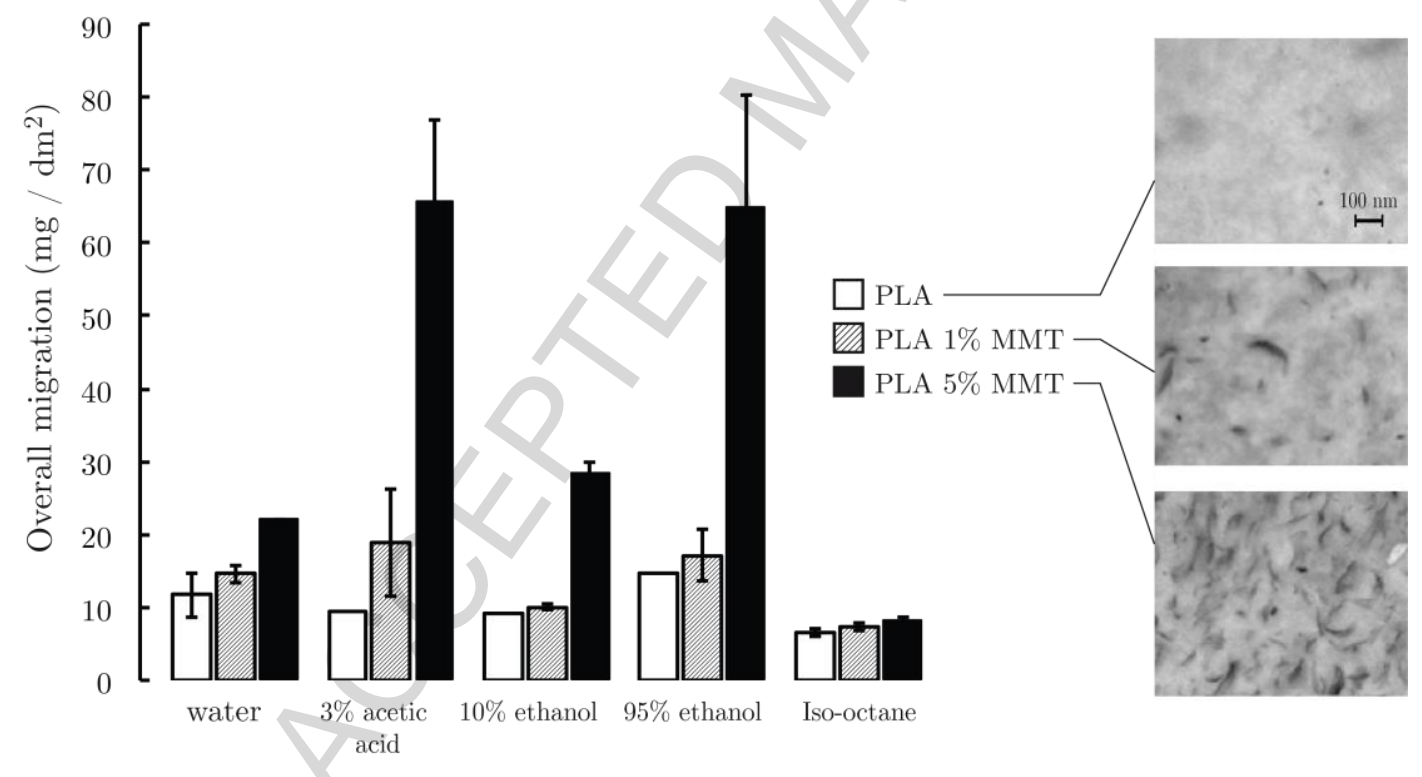

Fig. 6.

Measure of the extent of overall migration on PLA and PLA-based nanocomposite after 10-day contact with five food-simulating liquids at $40^{\circ} \mathrm{C}$. 
The stability of polylactide-based PNC had been extensively researches (Plackett, Andersen et al. 2003; Paul, Delcourt et al. 2005; Roy, Hakkarainen et al. 2012), but many studies were conducted over a long period of time at ambient temperature under controlled relative humidity, whereas the migration test conditions recommended by the EU regulation (generally 10 days of contact with the food simulant at $40^{\circ} \mathrm{C}$ ) dramatically increase the degradation rate of polymeric materials, and ENM incorporation could jeopardize the suitability of the PNC for food contact applications.

The impact of ENM on the potentially health-hazardous migration of chemical substances such as plastic additives is the second safety issue to factor into the assessment of packaging material compliance. The migration process can be considered as a combination of the diffusion of chemical additives through the polymers and the desorption of the diffused molecules from the polymer surface to the food or food simulants. In principle, the addition of an impermeable filler in a polymer matrix is expected to affect the solubility and diffusivity of a penetrant molecule (i) by introducing a path tortuosity when penetrants are forced to migrate around impermeable fillers and (ii) by modifying the interaction properties of the PNC due to the sorption/adsorption capacity of the nanoclays and their possible affinity for the diffusing molecules. Efforts have recently been led to enhance the knowledge of migration mechanisms by investigating the impact of ENM on the diffusion coefficient and partition coefficient of a panel of 8 lowmolecular-weight molecules representative of plastic additives in food-packaging systems including PNC (linear low-density polyethylene including 5\% of MMT) and different food-simulating liquids (Nasiri, Peyron et al. 2016). Results showed that apparent diffusivity $\left(D_{\mathrm{ap}}\right)$ was significantly reduced by the incorporation of MMT in the LLDPE-based packaging in the case of contact with aqueous simulants but not when when PNC is set in (Bharadwaj 2001) compared to the values predicted from tortuosity-based models assuming a regular arrangement of parallel nanoplatelets (Nielsen 1967; Cussler, Hughes et al. 1988; Moggridge, Lape et al. 2003; Lape, Nuxoll et al. 2004) or random spatial positioning of orientated flakes (Bharadwaj 2001) which proposed a modified form of the Nielsen's equation in order to take into account the angle of orientation ( $\square$ ) of the platelets with the surface of diffusion. 


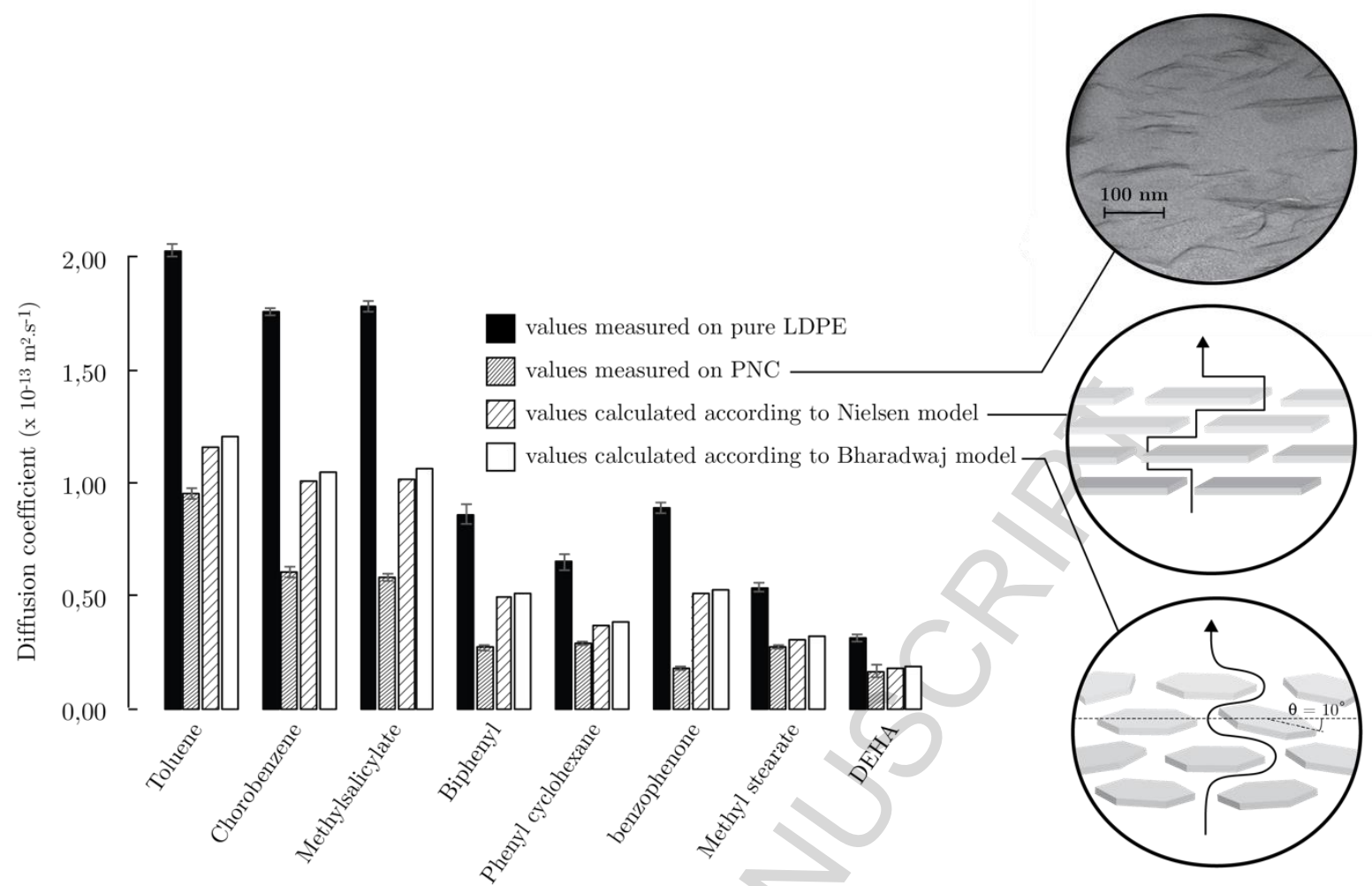

Fig. 7.

Apparent diffusivities measured on pure LDPE and LDPE-based nanocomposites including $5 \%$ of MMT in contact with $10 \%$ ethanol compared to the predicted values determined using analytical tortuositybased models.

The difference observed between values issued from experimental determination and values simulated using tortuosity-based predictive models argue in favor of a significant influence of migrant adsorption by the nanoclays in decreasing $D_{\text {ap }}$. The affinity of the diffusing molecules for nanoparticles is clearly dependant of their binding capacity and, consequently, their polarity (Nasiri, Peyron et al. 2016).

This statement is evidenced by the fact that the partition coefficient $\left(K_{\mathrm{PL}}=\frac{C_{\mathrm{PNC}}}{C_{\text {simulant }}}\right)$ of the eight selected additives proved to be influenced by MMT addition with contrasted effects depending on their polarity and the nature of food simulant (aqueous/fatty). Overall, while most of the $K_{\mathrm{PL}}$ values were increased by the presence of nanoclays, some additives revealed an increasing affinity for the fatty food simulant in when MMT was included in the packaging film. This statement requires special consideration of the 
safety impact of ENM addition as a function of the transport properties of the material. In the case of high-barrier polymers (polystyrene, polyethylene naphthalate, polyethylene terephthalate and polyamide) for which partition equilibrium is reached at a long contact time exceeding the shelf life of the foodstuff, the extent of migration is more specifically related to the diffusion coefficient of the contaminant. The addition of ENM in such polymers does not have detrimental effects in terms of food contamination by chemical substances. This means that the implementation of migration estimation models recognized by the EU regulation on common plastic materials (European Commission 2011) and based on "worst-case" scenario using an overestimation of the diffusion coefficient remain applicable to the risk assessment of such nanocomposite packaging.

In contrast, caution should be exercised in the case of low-barrier PNC e(specially polyolefin-based materials) that reach equilibrium within a few days and for which foodstuff contamination is correlated to the partition coefficient. Regarding the contrasted influence of MMT inclusion on the partitioning of substances, the case-by-case approach recommended by the current EU regulation for exposure evaluation on PNCs remain suitable to ensure consumer protection against chemical contamination.

\section{Conclusion}

Given the diversity of nanocomposite materials used for packaging applications, the assessment of consumer exposure is a key part of safety concerns that should be led via a multi-criteria analysis. Beyond the simple question of nanoparticle migration, the impact of incorporating ENM in a food packaging material has to be investigated in terms of their influence on the inertia of the polymeric material. Preliminary initiatives addressing this challenge have revealed the complexity of the issue and evidenced the possible antagonistic effects induced by the presence of ENM , which could result in both modification of the material's transport properties (by decreasing the diffusivity and modulating the affinity of low-molecular-weight additives for the packaging) and in structural change of the polymer chains (by activating hydrolysis reactions and/or activating their crystallization). Based on the state of the knowledge, it remains difficult to establish constitutive relations allowing to predict the ENMgenerated modification of behaviour on a polymeric matrix. In addition to a hazard classification of 
nanosubstances to underpin universal risk management, research now needs to progress on identifying the physical law(s) controlling PNC transport properties and then developing the next generation of food nanopackaging solutions using a "safe-by-design" approach with direct benefits for consumer safety.

\section{Controlling the presence of the food additive titanium dioxide and its fate after ingestion}

A range of inorganic additives including titanium dioxide $\left(\mathrm{TiO}_{2}\right)$ is available for food applications, nutraceuticals and supplements. $\mathrm{TiO}_{2}$ is used as a white pigment in processed foods, as described in the recent EFSA report (EFSA 2016). $\mathrm{TiO}_{2}$ has been in the spotlight for years, as it is totally exogenous to our organism, has been classified as possibly carcinogenic by inhalation to humans by the International Agency for Research on Cancer (IARC) since 2006, and it may be formed very small particles that have raised concerns due to their potential ability to cross biological barriers. Here we present the approach used in our lab to analyze the characteristics of food-grade titanium dioxide extracted from food products, together with pointers on the fate of the particles after ingestion.

\section{Titanium dioxide as ingredient (E171) \\ Identifying titanium dioxide in the coating of sweets}

Searching for very small particles in a food matrix can be a really hard task. Investigating titanium dioxide makes it easier, as it is usually at the surface of confectionery and gives a strong signal by Raman spectroscopy when in anatase form. By chance, this form is widely used in food additives (Peters, van Bemmel et al. 2014; Yang, Doudrick et al. 2014; Dudefoi, Terrisse et al. 2017). We thus used this method to discriminate food products containing $\mathrm{TiO}_{2}$. The procedure was applied to a kind of sweets formed of a stick of gum surrounded by a layer of liquorice which is itself covered by a white coating (see a crosssection of one piece in Fig. 8). When the piece was illuminated with a monochromatic laser beam (Fig. 8), the light, which was inelastically scattered, yields the Raman scattering and its wavelength depended on molecular vibrations and phonons at the surface layer. The spectrum of a piece of the sweet is given 
in Fig. 8, which shows a lot of peaks between $2800-3000$ and $50-1500 \mathrm{~cm}^{-1}$ corresponding to the vibration modes of organic molecules $\left(\mathrm{v}(\mathrm{C}-\mathrm{H})\right.$ and $\left.\delta\left(\mathrm{CH}_{2}\right)\right)$. At low wavenumbers, it also shows the typical fingerprints of $\mathrm{TiO}_{2}$ anatase, centred at 144,399, 513 and $639 \mathrm{~cm}^{-1}$ (Ohsaka, Izumi et al. 1978), confirming the presence of $\mathrm{TiO}_{2}$ in the coating of the sweet. Once the presence of $\mathrm{TiO}_{2}$ was detected, the confectionery coating was removed by the protocol shown in Fig. 9, based on the insolubility of $\mathrm{TiO}_{2}$ in water. In a first step, the coating was stripped from the sweet by placing it in deionized water for 30 seconds and hand-shaking. Once the white layer of the coating was separated from the gum, a waterwashing step was performed to separate $\mathrm{TiO}_{2}$ from physically adsorbed organic molecules. The washed coating was then characterized by FT-Raman spectroscopy, transmission electronic microscopy (TEM), inductively coupled plasma atomic emission spectrometry (ICP-AES) and X-ray diffraction (XRD) to learn more about the amount, shape, structure and purity of the nanoparticles.

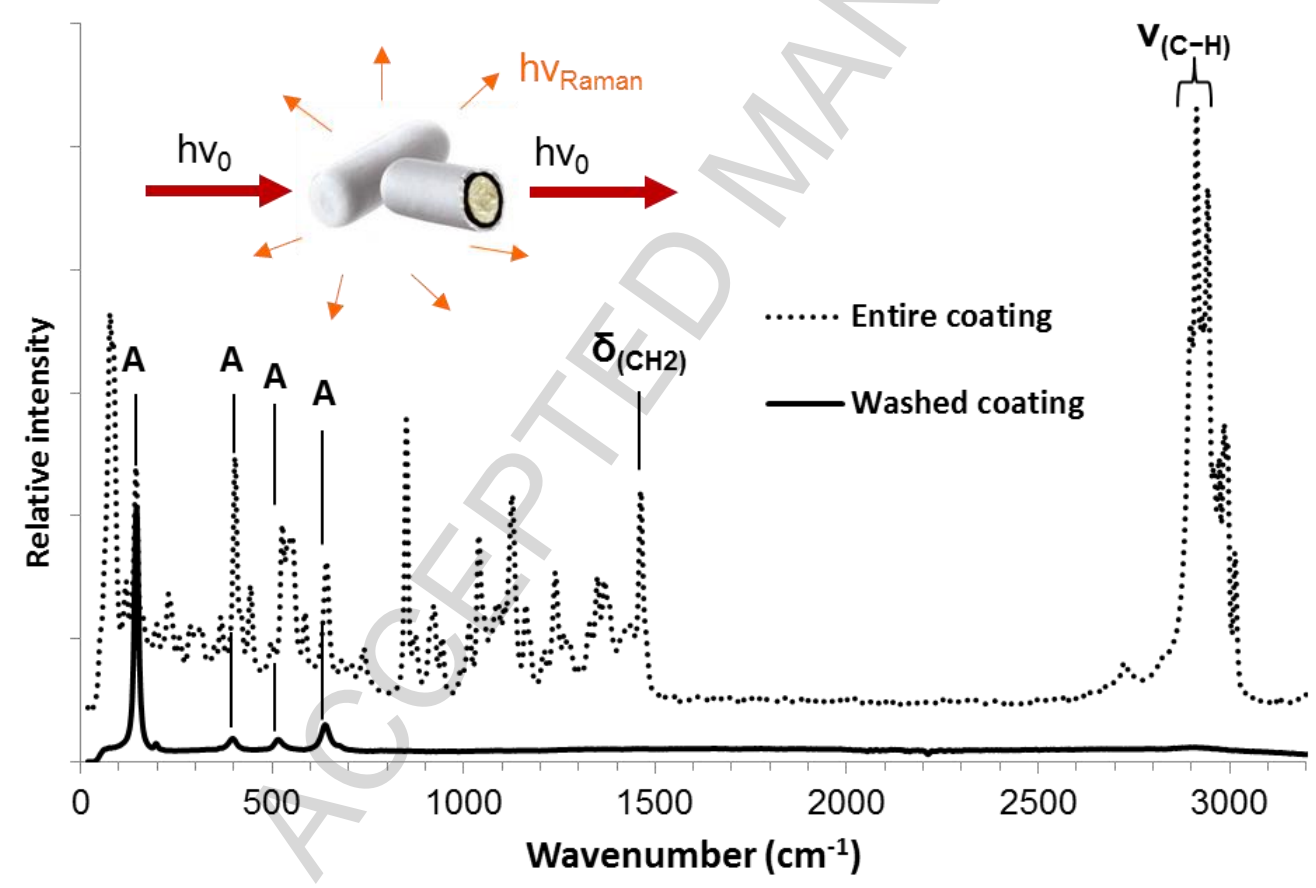

\section{Fig. 8.}

FT-Raman spectra of the coating of a sweet recorded before and after washing. Symbol A indexes the peak position of anatase $\mathrm{TiO}_{2} \cdot \mathrm{v}(\mathrm{C}-\mathrm{H})$ and $\delta\left(\mathrm{CH}_{2}\right)$ are the vibration modes associated to organic molecules. Spectra courtesy of IMN (Nantes, France). 
The washed coating was analyzed by FT-Raman spectroscopy (Fig. 8). All fingerprints of organic molecules disappeared after washing the extracts. Only the typical fingerprints of $\mathrm{TiO}_{2}$ anatase were visible, confirming that $\mathrm{TiO}_{2}$ was easily separated from the other ingredients.

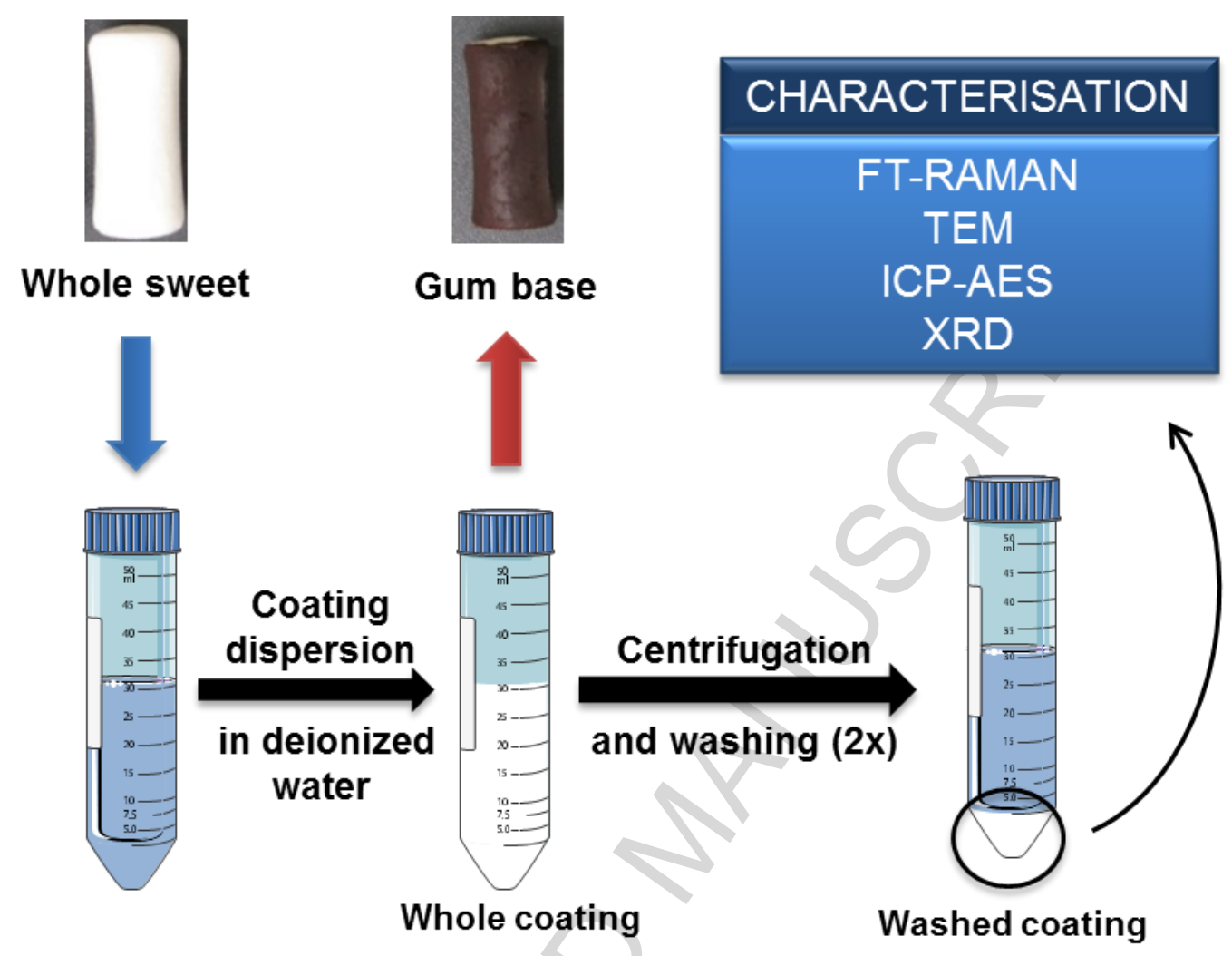

Fig. 9.

Steps in the characterization of $\mathrm{TiO}_{2}$ particles extracted from the coating of sweets (protocol adapted from Chen et al. (2013)).

As rutile is less easily identified by Raman than anatase, the nature of the crystalline phase of $\mathrm{TiO}_{2}$ in the coating of the sweet was also confirmed by XRD measurements (Fig. 10). The main crystalline structure detected was the anatase phase $\left(2 \theta=25.30^{\circ}\right)$ with some traces of rutile (reflection $(110)$ at $\left.2 \theta=27.41^{\circ}\right)$. This composition is similar to that found in chewing-gums (Chen, Cheng et al. 2013). The diffractogram exhibits one additional signal at $2 \theta=28.96^{\circ}$ which can be attributed to talc, a natural magnesium silicate used as anti-caking agent. 


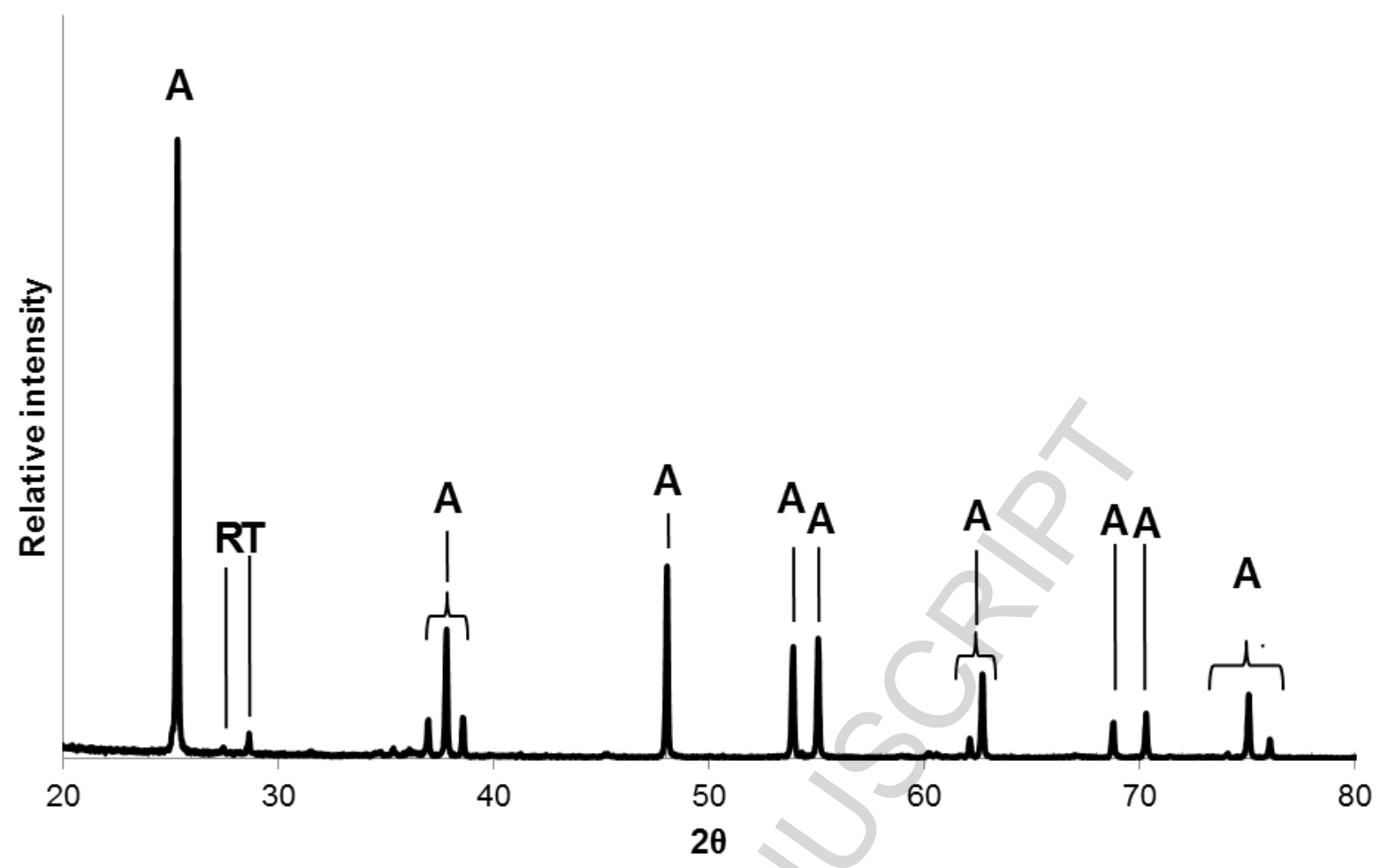

Fig. 10.

X-ray diffraction patterns of $\mathrm{TiO}_{2}$ extracted from the coating of sweets. Assignment was carried out against the reference patterns of anatase $\mathrm{TiO}_{2}$ (JCPDS 89-4921) and rutile $\mathrm{TiO}_{2}$ (JCPDS 89-4202). A is for anatase, $\mathrm{R}$ is for rutile, $\mathrm{T}$ is for talc. Diffractogram courtesy of IMN (Nantes, France).

\section{Characterization of nanoparticles by transmission electron microscopy}

The size and percentage of nanoparticles contained in the washed coating were determined by TEM in the same conditions as in a previous study performed in our lab (Dudefoi, Terrisse et al. 2017). Analysis of the TEM images (Fig. 11) showed the presence of $34 \% \mathrm{TiO}_{2}$ nanoparticles in the sweet coating, which is consistent with values found in native E171 powders or food products (Weir, Westerhoff et al. 2012; Chen, Cheng et al. 2013; Dudefoi, Terrisse et al. 2017). This amount is below the cut-off threshold (50\%) above which the labelling of nanomaterial is required in accordance with the current definition of nanomaterial. In addition to $\mathrm{TiO}_{2}$, we also identified larger objects (>500 nm) containing $\mathrm{Mg}$, $\mathrm{Si}$ and $\mathrm{Al}$ (determined by energy-dispersive X-ray spectroscopy EDX), which could correspond to the talc identified by XRD. The presence of aluminium in talc is usual and dependent on the kind of deposits. 


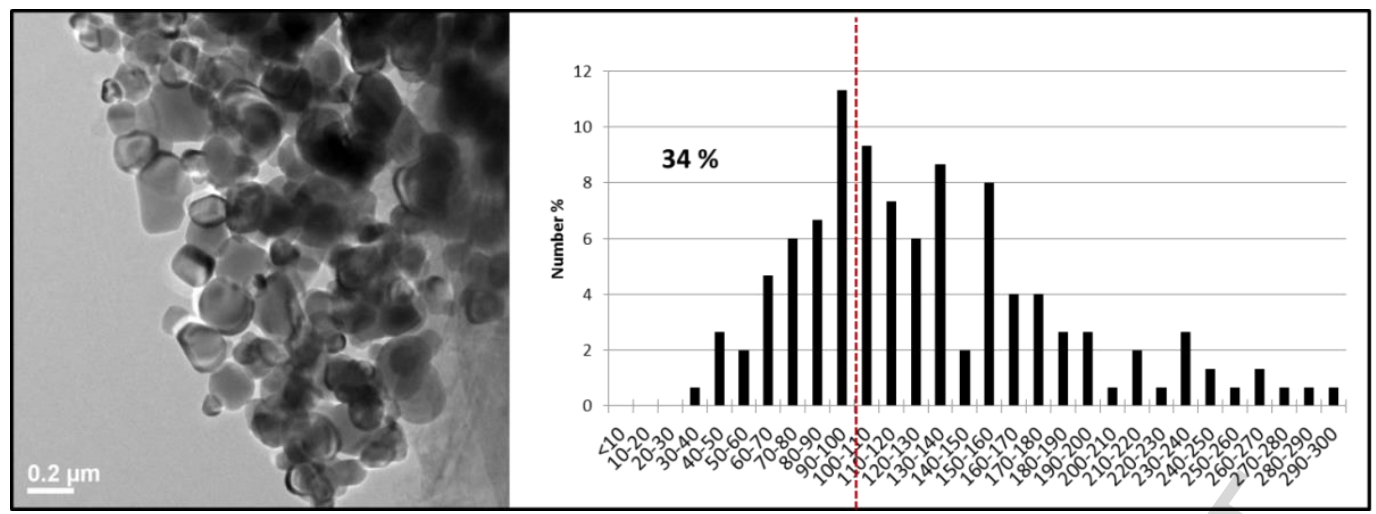

Fig. 11.

TEM observation and number-based size distribution analyses of $\mathrm{TiO}_{2}$ particles extracted from the coatings of sweets. Image courtesy of IMN (Nantes, France).

\section{Quantification of $\mathrm{TiO}_{2}$ by ICP-AES}

The washed coating was analyzed by ICP-AES to determine its elemental composition in $\mathrm{Ti}, \mathrm{Ca}, \mathrm{Si}, \mathrm{Al}$ and $\mathrm{P}$ (Error! Reference source not found.). The amount of $\mathrm{TiO}_{2}$ per piece of sweet was determined from the concentration of Ti normalized to the weight of a sweet (Error! Reference source not found.). In line with previous data, the washed coating of the sweet was composed of $68 \% \mathrm{w} / \mathrm{w} \mathrm{TiO}$, i.e. $0.27 \mathrm{mg}$ of $\mathrm{TiO}_{2} / \mathrm{g}$ sweet. This value is in the low range of concentrations quantified in various food products $(0.12-$ $2.64 \mathrm{mg} / \mathrm{g}$ of gum in Weir, Westerhoff et al. 2012), 1.51-3.88 mg/g chewing gum in Chen, Cheng et al. 2013), $0.01 \mathrm{mg} \mathrm{Ti/g}$ for a white-topped cookie to $5.4 \mathrm{mg} \mathrm{Ti} / \mathrm{g}$ product for a chewing gum in Peters, Bemmel et al. 2014). Normalized to a piece of sweet, the amount of $\mathrm{TiO}_{2}$ in the coating was $0.88 \mathrm{mg}$, i.e. $0.03 \%$ of the total weight of the sweet, in accordance with the values found by Lomer et al. (2000) in various food products $(0.045-0.782 \%)$ and Wang et al. (2013) in chewing gums. The presence of $\mathrm{Al}$, Si and Mg were confirmed by ICP-AES measurements, at 9.15, 72.78 and $35.14 \mathrm{mg} / \mathrm{g}$ of washed coating, respectively. The presence of $\mathrm{P}$ seems typical of food-grade forms of $\mathrm{TiO}_{2}$ and was identified as a phosphate species (Dudefoi, Terrisse et al. 2017).

Table 1. 
Elemental composition by ICP-AES of the washed coating of sweets, expressed in mg of element per g of dry coating.

\begin{tabular}{ll}
\hline Element & $\begin{array}{l}\text { Sweet }(\mathrm{mg} / \mathrm{g} \\
\text { of washed } \\
\text { coating) }\end{array}$ \\
\hline $\mathrm{Al}$ & 9.15 \\
$\mathrm{Ca}$ & 1.20 \\
$\mathrm{Si}$ & 72.78 \\
$\mathrm{P}$ & 0.74 \\
$\mathrm{Ti}$ & 406.11 \\
\hline
\end{tabular}

Considering both the percentage of nanoparticles and the amount of $\mathrm{TiO}_{2}$ within the coating of this sweet, we estimated the amount of nano- $\mathrm{TiO}_{2}$ per gram of gum and per gum (Table 2). The ingestion of one sweet represents an ingestion of $0.05 \mathrm{mg}$ of $\mathrm{TiO}_{2} \mathrm{NPs}$, i.e. $3.8 \times 10^{13}$ nanoparticles. This value is close to that found in other food products $\left(4 \cdot 10^{13}\right.$ in Lomer et al.(2000)).

Table 2.

Estimation of the intake of titanium dioxide (whole form and nano-form) after the ingestion of one piece of sweet. Amount of $\mathrm{TiO}_{2}$ nanoparticles per sweet were estimated from size distributions and with the assumption that $\mathrm{TiO}_{2}$ particles are spherical in a first approximation.

\begin{tabular}{ll}
\hline Content & Sweet \\
\hline $\mathrm{TiO}_{2} \%$ in washed coating & 67.76 \\
$\mathrm{TiO}_{2}$ (mg/g of sweet) & 0.27 \\
$\mathrm{TiO}_{2}$ (mg/sweet) & 0.88 \\
$\mathrm{TiO}_{2}$ wt \% in sweet & 0.03 \\
$\mathrm{Nano}^{-\mathrm{TiO}_{2}}$ (mg/sweet) & 0.05 \\
Nano- $^{\mathrm{TiO}}$ & (nbr/sweet) \\
\hline
\end{tabular}

According to a study on the consumption of $\mathrm{TiO}_{2}$ in Germany, the ingestion of $\mathrm{TiO}_{2}$ from chewing-gums represents a small amount compared to any other intake (Bachler, von Goetz et al. 2015). For example, savoury sauces, dressings, soft drinks and cheese represent more than $75 \%$ of the intake of titanium dioxide in adults, whereas consumer perceptions are more focused on confectionery. Daily median intake is thus between 0.5 and $1.0 \mathrm{mg} / \mathrm{kg} \mathrm{b.w.} \mathrm{for} \mathrm{all} \mathrm{age} \mathrm{groups} \mathrm{(from} \mathrm{toddlers} \mathrm{to} \mathrm{seniors),} \mathrm{except} \mathrm{for}$ 
children between 3 and 9 years who have the highest titanium intake of all age classes (approximately $2.0 \mathrm{mg} / \mathrm{kg}$ b.w.) (Bachler, von Goetz et al. 2015). As noted by the authors, the actual amount of ingested $\mathrm{TiO}_{2}$ may be overestimated due to a bias towards products with high titanium levels. Moreover, exposure is significantly different between countries due to a significant difference in consumption habits, for example between the US and the UK (Weir, Westerhoff et al. 2012). Furthermore, ICP devices are expected to gain sensitivity and food composition is expected to change, and we have experienced these trends ourselves: i) $\mathrm{TiO}_{2}$ was not previously found in Wrigley-brand chewing gums (Lomer, Thompson et al. 2000) yet recently found in work performed at our lab and elsewhere (Athinarayanan, Alshatwi et al. 2015; Dudefoi, Terrisse et al. 2017)); ii) $\mathrm{TiO}_{2}$ is no longer found in Smarties, based on work by us on the listed ingredients and a previous review (Rydström Lundin 2012).

\section{Physical-chemical properties of titanium dioxide E171}

The physical-chemical characteristics of particles, including morphology (spherical, cylindrical), size (smaller or larger than $<100$ ), charge (negative, neutral or positive), structure (crystallinity), agglomeration (aggregates, agglomerates, primary particles) and surface composition, are assumed or demonstrated to play a role in nanoparticle uptake through the gut (EFSA Scientific Committee 2011). For this reason, we set out to characterize the washed coating of sweets and chewing-gums. However, the amount of $\mathrm{TiO}_{2}$ per sweet was very small $(0.88 \mathrm{mg} / \mathrm{sweet})$ and its extraction from the coating could not be done without the co-extraction of inorganic substances or with a chemical treatment that would have modified the surface chemistry of the extracted particles. To get round this problem and obtain the physicochemical properties of $\mathrm{TiO}_{2}$ particles, we turned to the raw powder of food-grade $\mathrm{TiO}_{2}$ additive E171. We got several samples sold in Europe and analyzed them by a large panel of tools including TEM, XRD, laser scattering particle size distribution analysis, X-ray photoelectron spectrometry (XPS), zeta potential measurements, Raman and Infrared spectroscopies, ICP-AES, diffuse reflectance infrared Fourier-transform spectroscopy (DRIFTS) and surface area analysis. As almost nothing is known about these food-grade particles, we compared their properties with the well-known P25 particles which serve as reference (Orts-Gil, Natte et al. 2013). Our results showed that E171 samples contain a fraction of 
nanoparticles (ranging from 17 to $36 \%$ in number) below the threshold (50\%) defining the labelling of nanomaterial (Dudefoi, Terrisse et al. 2017), in accordance with the results found on the sweets. These powders are also characterized by a low specific surface area, a pure crystalline-phase anatase, a low isoelectric point (around 4.1) related to the phosphate found at its surface, and agglomeration in water. Comparison of the physical-chemical characteristics of both E171 and P25 samples of $\mathrm{TiO}_{2}$ is shown in Fig. 12. The P25sample, which is a non-food grade material but serves as a reference material, appears very different from the food-grade sample. E171 is not therefore the best material to use when studying human exposure by ingestion, or should be at least investigated in parallel to the reference material P25. This chart also emphasises that the concern about nano-forms is not only related to the physical form (NPs) but also to the the chemistry of the particles.

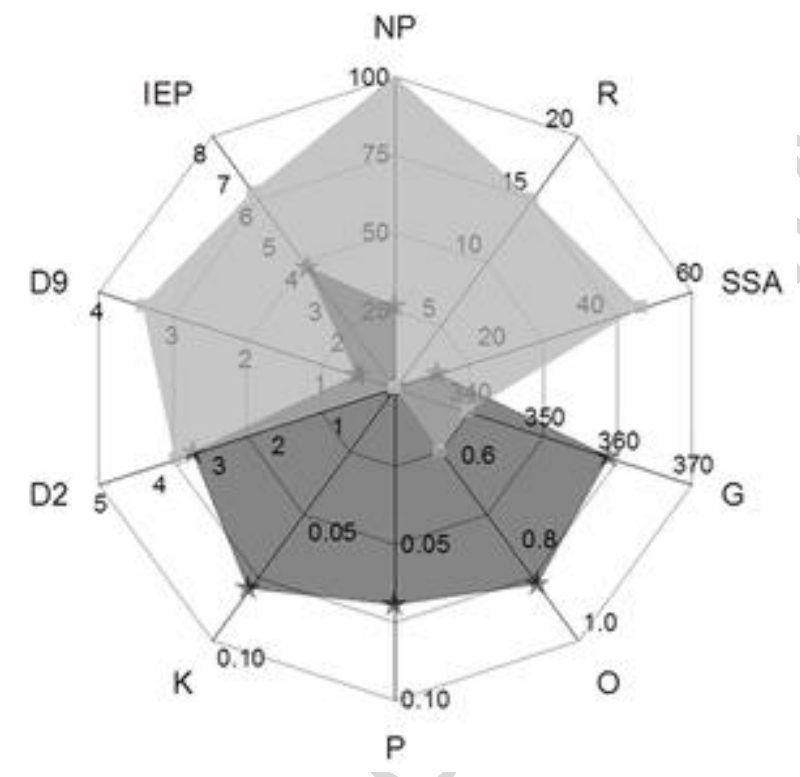

Fig. 12.

Radar chart showing specific surface area (SSA), isoelectric point (IEP), percentage of rutile (the complementary part of anatase to $100 \%$ ), threshold in reflectance (G), surface composition of elements relative to titanium ( $\mathrm{O}, \mathrm{P}$ and $\mathrm{K})$, the granulometric diameter at $\mathrm{pH} 2$ and 9 ( $\mathrm{D} 2$ and $\mathrm{D} 9$ respectively) of titanium dioxide E171 (dark grey stars and area, data averaged for several batches described individually in Dudefoi et al. (2017)) and P25 (light grey squares and area). 


\section{Fate of titanium dioxide after ingestion}

This part summarizes the main steps in the transformation of $\mathrm{TiO}_{2}$ particles in the digestive tract, the translocation pathway, and finally its biodistribution/bioaccumulation in the body, without considering its adverse effects which are discussed elsewhere (Bergin and Witzmann 2013; Jovanović 2015; EFSA Panel on Food Additives and Nutrient Sources added to Food 2016; McCracken, Dutta et al. 2016).

\section{Transformations in the gastro-intestinal tract}

When the process of chewing $\mathrm{TiO}_{2}$-coated chewing-gums was over, only a small amount of $\mathrm{TiO}_{2}$ remained in the gum (maximum $7.2 \pm 0.6 \%$ ), which means more than $93 \%$ of the intake of $\mathrm{TiO}_{2}$ into the body happened after only 10 minutes of chewing, i.e. $1.5 \mathrm{mg}$ for one piece of chewing-gum (Chen, Cheng et al. 2013). Our previous results on $\mathrm{TiO}_{2}$ extraction from sweets showed that $\mathrm{TiO}_{2}$ was easily separated from the other ingredients and could thus be considered as naked when entering into contact with digestive fluids. While the digestive system is able to transform most food into absorbable structures, inorganic particles like $\mathrm{TiO}_{2}$ cannot be metabolized (Zhao, Hallin et al. 2014). Nevertheless, they do undergo the different physical-chemical conditions along the alimentary tract. In the oral cavity, particles already had a high agglomeration tendency (Teubl, Schimpel et al. 2015), but 10\% were still available in the nanosized range and penetrated the upper and lower buccal epithelium, independently of hydrophilicity (Tay, Fang et al. 2014; Teubl, Leitinger et al. 2014; Teubl, Schimpel et al. 2015). Once introduced directly in the gastric fluid, $\mathrm{TiO}_{2}$ NPs agglomerate anyway (Jones, Morton et al. 2015). In all the digestive fluids, $\mathrm{TiO}_{2}$ particles could still exist as primary entities, but the percentage of nano- $\mathrm{TiO}_{2}$ is lower (Chen, Cheng et al. 2013), especially in the gastric fluid. This was attributed to the presence of proteins and electrolytes (Chen, Cheng et al. 2013; Jones, Morton et al. 2015). Further agglomeration was observed when $\mathrm{TiO}_{2}$ was dispersed in polymeric or elemental foods (Jones, Morton et al. 2015). Finally, a high percentage (roughly $95 \%$ ) of $\mathrm{TiO}_{2}$ is excreted from the body in faeces (Cho, Kang et al. 2013; MacNicoll, Kelly et al. 2015). 


\section{Crossing biological barriers}

The amount of $\mathrm{TiO}_{2}$ that gets absorbed by the body is actually extremely low (Cho, Kang et al. 2013; Jovanović 2015). This was first proved by detecting up to $43.2 \pm 4.6 \mu \mathrm{g} / \mathrm{L}$ of $\mathrm{TiO}_{2}$ in the blood of volunteers after oral ingestion of $22.9 \mathrm{mg}$ of $\mathrm{TiO}_{2}$ incorporated in gelatin capsules (Böckmann, Lahl et al. 2000). If the ingested amount had totally crossed the intestinal barrier, the amount for an adult with $6 \mathrm{~L}$ of blood would amount to $3.8 \mathrm{mg} / \mathrm{L}$, i.e. roughly 100 times more than the amount found in reality, which confirms the low absorption rate. This translocation was confirmed by Pele et al (2015) but disconfirmed by Jones et al. (2015). The discrepancy can be explained by the time of tests, the formulation, and the type of particles. First, the collection of human blood samples in the study of Jones et al. (2015) was performed $2,4,24$ and $48 \mathrm{~h}$ after dosing while peak level of $\mathrm{TiO}_{2}$ was noted between 4 and $12 \mathrm{~h}$ for all volunteers in the study of Böckmann et al. (2000). Second, levels in blood depend on type of formulation $\left(\mathrm{TiO}_{2}\right.$ encapsulated in gelatin capsules or not; Böckmann, Lahl et al. 2000). Third, the particles used in these two studies were different from a physical-chemical point of view, which may modify particle reactivity, agglomeration and the pathway/kinetics used to cross the physiological barriers.

Many studies converge on the fact that the main mechanism of $\mathrm{TiO}_{2}$ translocation involves the M-cellrich layer of Peyer patches, which are epithelial cells specialized for the transcytosis of macromolecules and particles (Powell, Faria et al. 2010; Bergin and Witzmann 2013; Brun, Barreau et al. 2014; Bellmann, Carlander et al. 2015; Higashisaka, Yoshioka et al. 2015; McCracken, Dutta et al. 2016). However, the mechanism of translocation is still under debate, since contradictory results were obtained with in vitro cells (Koeneman, Zhang et al. 2010; Gitrowski, Al-Jubory et al. 2014; Janer, Mas del Molino et al. 2014; Jones, Morton et al. 2015; MacNicoll, Kelly et al. 2015).

\section{Biodistribution and bioaccumulation}

Once it has entered the bloodstream, $\mathrm{TiO}_{2}$ can diffuse by blood circulation throughout the organism. where it is finally mainly found in liver, the main organ where exogenous chemicals are metabolized and eventually excreted, and kidney, the organ involved in the excretion of metabolic wastes (Chang, Zhang et al. 2013). The most recent studies tend to confirm this fact (Cho, Kang et al. 2013; Park, Lee et al. 
2014; Disdier, Devoy et al. 2015), with sometimes poor clearance (Umbreit, Francke-Carroll et al. 2012; Hummel, Kindermann et al. 2014; Disdier, Devoy et al. 2015) and sometimes a decrease of $\mathrm{TiO}_{2}$ levels down to control levels (Fabian, Landsiedel et al. 2008). Studies on children suspected of having inflammatory bowel disease showed that the amount of pigment in Peyer patches in the terminal ileum becomes denser with increasing age (Hummel, Kindermann et al. 2014), indicating poor clearance.

\section{Conclusion}

Titanium dioxide is a food additive widely used in processed foods to improve the color of end-products. After negative toxicity tests, titanium dioxide found its way into the composition of processed foods a very long time ago, is not labeled as a nanomaterial due to its low number of nanoparticles, and is mostly (95\%) excreted from the body. In contrast to nanofoods, including nanoliposomes or solid lipid nanoparticles which are used as delivery systems for vitamins or micronutrients, $\mathrm{TiO}_{2}$ as food additive has no nutritional value but has a role in the perception of food. Following an in-depth re-evaluation of this compound based on the data available in early 2016, the European Food Safety Agency had no scientific reason to reject this inorganic compound as a food additive. Scientific questions that have yet to be answered include the impact of such particles from long-term exposure (as in work developed by Bettini et al. (2017)) and the fate of the non-excreted fraction (location, clearance, effect) as well as its nanoparticle content. Given the demonstrated differences between E171 and P25 materials, we strongly urge researchers studying the biological effects of ingested $\mathrm{TiO}_{2}$ to consider the food-grade forms in addition to P25 forms. Learning whether particles develop a corona of adsorbed proteins in the digestive fluids is one of the goals currently being tackled in our lab to better understand the absorption of this compound through the intestinal barrier. 


\section{Future for nanotechnology}

Nanotechnology offers promising new possibilities in the agriculture and food industry where it has concrete applications, but there is also a lack of awareness and uncertainty about the balance between potential benefits on one side and potential risks and possible long-term side effects on the other. Consumer perception of health and safety concerns is central to the uptake or rejection of this new technology. The number of questions, not still well taken into account and financed, on the identification of nanomaterials in complex matrices, on their short- and long -term behavior in humans and the environment has increased both citizen and scientist concerns but at the same time fueled a lack of transparency in commercial communications and in institutional documents.

For the future, research should aim to ensure that nano-devices will help develop cheap and highly integrated diagnostic systems of higher sensitivity, specificity and reliability for chemical, biological and medical analysis to play a major role in biodegradable packaging, protective coatings, food safety monitoring, and also ensure that nanotoxicology will provide a thorough nanoscale hazard and risk analysis before nanotechnology is exploited by industry and used by consumers. Nano should not be commercialized and marketed in food and agriculture until nano-specific safety guidelines and laws have been issued, nano-specific standard specifications have been agreed, and nano-specific regulatory issues for food and environment technology have been established with public input to decision-making. Better consumer awareness on nanoscience and nanotechnologies is equally vital.

\section{Acknowledgments}

The $\mathrm{TiO}_{2}$ work was carried out in the framework of the Labex Serenade project (ANR-11-LABX-0064) and A*MIDEX project (ANR-11-IDEX-0001-02), funded by the French Government “Investissements d'Avenir" program managed by the French National Research Agency (ANR). The authors thank Hélène Terrisse, Eric Gautron and Florin Popa from the Institut des Matériaux Jean Rouxel IMN (Nantes, France) for their help in performing ICP-AES, TEM and XRD measurements. 


\section{References}

Administration, U. S. F. a. D. (2014). Food and Drug Administration - guidance for industry considering whether an FDA-regulated product involves the application of nanotechnology. Biotechnology Law Report, U.S. Food and Drug Administration. 30: 613-616.

Ahola, S., X. Turon, et al. (2008). "Enzymatic hydrolysis of native cellulose nanofibrils and other cellulose model films: effect of surface structure." Langmuir 21(20): 11592-9.

Alexandre, M. and P. Dubois (2000). "Polymer-layered silicate nanocomposites: Preparation, properties and uses of a new class of materials." Materials Science and Engineering R: Reports 28: 1-63.

Alvarez, C., F. M. Reyes-Sosa, et al. (2016). "Enzymatic hydrolysis of biomass from wood." Microbial Biotechnology 9: 149-155.

Arantes, V., K. Gourlay, et al. (2014). "The enzymatic hydrolysis of pretreated pulp fibers predominantly involves "peeling/erosion" modes of action." Biotechnology for Biofuels 7(87): 2-10.

Artiaga, G., K. Ramos, et al. (2015). "Migration and characterisation of nanosilver from food containers by AF4-ICP-MS." Food Chemistry 166: 76-85.

Athinarayanan, J., A. A. Alshatwi, et al. (2015). "Identification of nanoscale ingredients in commercial food products and their induction of mitochondrially mediated cytotoxic effects on human mesenchymal stem cells." Journal of Food Science 80(2): N459-N464.

Authority, E. F. S. (2005). Opinion of the Scientific Panel on food additives, flavourings, processing aids and materials in contact with food (AFC) related to a 7th list of substances for food contact materials. EFSA Journal, European Food Safety Authority. 3: n/a--n/a.

Authority, E. F. S. (2016). Scientific opinion on the re-evaluation of silver (E 174) as food additive. EFSA Journal, European Food Safety Authority. 14: 4364-4428.

Azzam, F., C. Moreau, et al. (2014). "Cellulose nanofibril-based multilayered thin films: effect of ionic strength on porosity, swelling, and optical properties." Langmuir 30(27): 8091-8100.

Azzam, F., C. Moreau, et al. (2015). "Reversible modification of structure and properties of cellulose nanofibril-based multi layered thin films induced by postassembly acid treatment." Langmuir 31(9): 2800-2807.

Bachler, G., N. von Goetz, et al. (2015). "Using physiologically based pharmacokinetic (PBPK) modeling for dietary risk assessment of titanium dioxide (TiO2) nanoparticles." Nanotoxicology 9(3): 373-380.

Barth, J. V., G. Costantini, et al. (2005). "Engineering atomic and molecular nanostructures at surfaces." Nature 437(7059): 671-679.

Bellmann, S., D. Carlander, et al. (2015). "Mammalian gastrointestinal tract parameters modulating the integrity, surface properties, and absorption of food-relevant nanomaterials." Wiley Interdisciplinary Reviews-Nanomedicine and Nanobiotechnology 7(5): 609-622.

Bergin, I. L. and F. a. Witzmann (2013). "Nanoparticle toxicity by the gastrointestinal route: evidence and knowledge gaps." International Journal of Biomedical Nanoscience and Nanotechnology 3: 163-210.

Bettini, S., E. Boutet-Robinet, et al. (2017). "Food-grade TiO2 impairs intestinal and systemic immune homeostasis, initiates preneoplastic lesions and promotes aberrant crypt development in the rat colon." Scientific Reports 7: 40373.

Bharadwaj, R. K. (2001). "Modeling the barrier properties of polymer-layered silicate nanocomposites." Macromolecules 26: 9189-9192.

Blodgett, K. B. (1934). "Monomolecular films of fatty acids on glass." Journal of the American Chemical Society 56(2): 495-495.

Blodgett, K. B. (1935). "Films built by depositing successive monomolecular layers on a solid surface." Journal of the American Chemical Society 57(6): 1007-1022.

Böckmann, J., H. Lahl, et al. (2000). "Blood titanium levels before and after oral administration titanium dioxide [in German]." Pharmazie 55(2): 140-143.

Boddohi, S., C. E. Killingsworth, et al. (2008). "Polyelectrolyte multilayer assembly as a function of ph and ionic strength using the polysaccharides chitosan and heparin." Biomacromolecules 9(7): 2021-2028. 
Borges, J. and J. F. Mano (2014). "Molecular interactions driving the layer-by-layer assembly of multilayers." Chemical Reviews 114: 8883-8942.

Bott, J., A. Störmer, et al. (2014). "A model study into the migration potential of nanoparticles from plastics nanocomposites for food contact." Food Packaging and Shelf Life 2: 73-80.

Bott, J., A. Strömer, et al. (2014). "A comprehensive study into the migration potential of nano silver particles from food contact polyolefins." ACS Symposium Series 1159: 51-70.

Bowles, M. and J. Lu (2014). "Removing the blinders: A literature review on the potential of nanoscale technologies for the management of supply chains." Technological Forecasting and Social Change 82: 190-198.

Brun, E., F. Barreau, et al. (2014). "Titanium dioxide nanoparticle impact and translocation through ex vivo, in vivo and in vitro gut epithelia." Particle and fibre toxicology 11(13).

Bumbudsanpharoke, N. and S. Ko (2015). "Nano-food packaging: an overview of market, migration research, and safety regulations." Journal of Food Science 80: R910-R923.

Carpita, N. and D. Gibeaut (1993). "Structural models of primary cell walls in flowering plants:

consistency of molecular structure with the physical properties of the walls during growth." The Plant Journal 3(1): 1-30.

Cathell, M. D. and C. L. Schauer (2007). "Structurally colored thin films of Ca2+-cross-linked alginate." Biomacromolecules 8(1): 33-41.

Cerclier, C., A. Guyomard-Lack, et al. (2011). "Coloured semi-reflective thin films for biomass-hydrolyzing enzyme detection." Advanced Materials: 1-5.

Cerclier, C. V., A. Guyomard-Lack, et al. (2013). "Xyloglucan-cellulose nanocrystal multilayered films: effect of film architecture on enzymatic hydrolysis." Biomacromolecules 14(10): 3599-3609.

Chang, X., Y. Zhang, et al. (2013). "Health effects of exposure to nano-TiO2: a meta-analysis of experimental studies." Nanoscale Research Letters 8(1): 1-10.

Chaudhry, Q., L. Castle, et al. (2008). "Assessment of current and projected applications of Nanotechnology for food contact materials in relation to consumer safety and regulatory implications." Final Report of the Project N ${ }^{\circ} \mathrm{A} 03063$ of the Central Science Laboratory: 1-93.

Chen, X.-X., B. Cheng, et al. (2013). "Characterization and preliminary toxicity assay of nano-titanium dioxide additive in sugar-coated chewing gum." Small 9(9-10): 1765-1774.

Cho, J. I., S. H. Lee, et al. (2011). "Detection and distribution of food-borne bacteria in ready-to-eat foods in Korea." Food Science and Biotechnology 20: 525-529.

Cho, W.-S., B.-C. Kang, et al. (2013). "Comparative absorption, distribution, and excretion of titanium dioxide and zinc oxide nanoparticles after repeated oral administration." Particle and Fibre Toxicology 10: 9.

Cochard, H. (2006). "Cavitation in trees." Comptes Rendus Physique 7(9): 1018-1026.

Commission, E. (2004). Regulation (EC) No 1935/2004 of the European Parliament and of the Council of 27 October 2004 on materials and articles intended to come into contact with food. Offical Journal of the European Union, European Commission. 47: 4-17.

Commission, E. (2011). Commission Regulation (EU) No 10/2011 of 14 January 2011 on plastic materials and articles intended to come into contact with food. Offical Journal of the European Union, European Commission: 1-89.

Cosgrove, D. J. (2014). "Re-constructing our models of cellulose and primary cell wall assembly." Current Opinion in Plant Biology 22: 122-131.

Couture, L. and T. G. M. Vandeven (1991). "Hydrodynamic layer thickness of poly(ethylene oxide) adsorbed on polystyrene latex" Colloids and Surfaces 54(3-4): 245-260.

Cranston, E. D. and D. G. Gray (2006). "Morphological and optical characterization of polyelectrolyte multilayers incorporating nanocrystalline cellulose." Biomacromolecules 9(7): 2522-2530.

Cushen, M., J. Kerry, et al. (2014). "Evaluation and simulation of silver and copper nanoparticle migration from polyethylene nanocomposites to food and an associated exposure assessment." Journal of Agricultural and Food Chemistry 62: 1403-1411.

Cushen, M., J. Kerry, et al. (2014). "Silver migration from nanosilver and a commercially available zeolite filler polyethylene composites to food simulants." Food Additives \& Contaminants. Part A 31: 1132-1140. 
Cussler, E. L., S. E. Hughes, et al. (1988). "Barrier membranes." Journal of Membrane Science 38: 161-174. Dammak, A., C. Moreau, et al. (2013). "Elaboration of multilayered thin films based on cellulose nanocrystals and cationic xylans: application to xylanase activity detection." Holzforschung 67(5): 579586.

Dammak, A., B. Quemener, et al. (2015). "Exploring architecture of xyloglucan cellulose nanocrystal

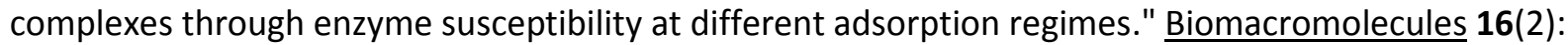
589-596.

De Witt, J. A. and T. G. M. Van de Ven (1992). "Kinetics and reversibility of the adsorption of poly(vinyl alcohol) onto polystyrene latex particles." Langmuir 8(3): 788-793.

Decher, G. (1997). "Fuzzy nanoassemblies: Toward layered polymeric multicomposites." Science 277(5330): 1232-1237.

Decher, G. and J. B. Schlenoff (2012). Layer-by-layer assembly (putting molecules to work). Multilayer Thin Films: Sequential Assembly of Nanocomposite Materials. G. D. a. J. B. Schlenoff, Wiley-VCH Verlag GmbH \& Co. KGaA: 1-21.

Disdier, C., J. Devoy, et al. (2015). "Tissue biodistribution of intravenously administrated titanium dioxide nanoparticles revealed blood-brain barrier clearance and brain inflammation in rat." Particle and Fibre Toxicology 12.

Dudefoi, W., H. Terrisse, et al. (2017). "Criteria to define a more relevant reference sample of titanium dioxide in the context of food: a multiscale approach." Food Additives \& Contaminants. Part A: accepted. Duncan, T. V. (2011). "Applications of nanotechnology in food packaging and food safety: Barrier materials, antimicrobials and sensors." Journal of Colloid and Interface Science 363: 1-24.

Echegoyen, Y. and C. Nerín (2013). "Nanoparticle release from nano-silver antimicrobial food containers." Food and Chemical Toxicology 62: 16-22.

EFSA ANS Panel (EFSA Panel on Food Additives and Nutrient Sources added to Food) (2016). "Scientific opinion on the re-evaluation of titanium dioxide (E 171) as a food additive." EFSA Journal 14(9): 83 pp. doi:10.2903/j.efsa.2016.4545.

EFSA Scientific Committee (2011). "Scientific opinion on guidance on the risk assessment of the application of nanoscience and nanotechnologies in the food and feed chain." EFSA Journal 9(5): 2140. Available online:

http://www.efsa.europa.eu/sites/default/files/scientific output/files/main documents/2140.pdf. Executive, E. U. (2011). "Commission recommendation of 18 October 2011 on the definition of nanomaterial (2011/696/EU)." Official Journal of the European Union: 38-40.

Fabian, E., R. Landsiedel, et al. (2008). "Tissue distribution and toxicity of intravenously administered titanium dioxide nanoparticles in rats." Archives of Toxicology 82(3): 151-157.

Farhoodi, M., S. M. Mousavi, et al. (2014). "Migration of aluminum and silicon from PET/clay nanocomposite bottles into acidic food simulant." Packaging Technology and Science 27: 161-168. Gitrowski, C., A. R. Al-Jubory, et al. (2014). "Uptake of different crystal structures of $\mathrm{TiO}_{2}$ nanoparticles by Caco-2 intestinal cells." Toxicology letters 226: 264-276.

Gontard, N., S. Peyron, et al. (2017). "Nanotechnologies for active and intelligent food packaging : opportunities and risks." Nanotechnologies for Agriculture and Foods: Past and Future. M. Axelos and M. Van De Voorde.

Guyomard-Lack, A., C. Cerclier, et al. (2012). "Nano-structured cellulose nanocrystals-xyloglucan multilayered films for the detection of cellulase activity." European Physical Journal Special Topics 213: 291-294

Guyomard-Lack, A., N. Delorme, et al. (2011). "Site-Selective surface modification using enzymatic soft lithography." Langmuir 27(12): 7629-7634.

Guyomard-Lack, A., C. Moreau, et al. (2012). "Patterning surface by site selective capture of biopolymer hydrogel beads." Colloids and Surfaces B-Biointerfaces 94: 369-373.

Habibi, Y., L. Foulon, et al. (2007). "Langmuir-Blodgett films of cellulose nanocrystals: Preparation and characterization." Journal of Colloid and Interface Science 316(2): 388-397. 
Handy, R. D. and B. J. Shaw (2007). "Toxic effects of nanoparticles and nanomaterials: Implications for public health, risk assessment and the public perception of nanotechnology." Health, Risk \& Society 9 : 125-144.

Higashisaka, K., Y. Yoshioka, et al. (2015). "Applications and safety of nanomaterials used in the food industry." Food Safety 3(2): 39-47.

Hiller, J., J. D. Medel, et al. (2002). "Reversibly erasable nanoporous anti-reflection coatings from polyelectrolyte multilayers." Nature Materials 1: 59-63.

Holmberg, M., J. Berg, et al. (1997). "Surface force studies of Langmuir-Blodgett cellulose films." Journal of Colloid and Interface Science 186(2): 369-381.

Huang, Y., S. Chen, et al. (2011). "Nanosilver migrated into food-simulating solutions from commercially available food fresh containers." Packaging Technology and Science 24: 291-297.

Hummel, T. Z., A. Kindermann, et al. (2014). "Exogenous pigment in Peyer patches of children suspected of having IBD." Journal of Pediatric Gastroenterology and Nutrition 58(4): 477-480.

Janer, G., E. Mas del Molino, et al. (2014). "Cell uptake and oral absorption of titanium dioxide nanoparticles." Toxicology Letters 228: 103-110.

Jean, B. (2014). Polymer-Cellulose Nanocrystals Multilayer Films. Handbook of Green Materials: 105-119. Jean, B., F. Dubreuil, et al. (2008). "Structural details of cellulose nanocrystals/polyelectrolytes multilayers probed by neutron reflectivity and AFM." Langmuir 24(7): 3452-3458.

Jean, B., L. Heux, et al. (2009). "Non-electrostatic building of biomimetic cellulose-xyloglucan multilayers." Langmuir 25(7): 3920-3923.

Jokar, M. and R. Abdul Rahman (2014). "Study of silver ion migration from melt-blended and layereddeposited silver polyethylene nanocomposite into food simulants and apple juice." Food Additives \& Contaminants: Part A 31: 734-742.

Jones, K., J. Morton, et al. (2015). "Human in vivo and in vitro studies on gastrointestinal absorption of titanium dioxide nanoparticles." Toxicology letters 233: 95-101.

Josefsson, P., G. Henriksson, et al. (2007). "The physical action of cellulases revealed by a quartz crystal microbalance study using ultrathin cellulose films and pure cellulases." Biomacromolecules 9(1): 249-254. Jovanović, B. (2015). "Critical review of public health regulations of titanium dioxide, a human food additive." Integrated Environmental Assessment and Management 11(1): 10-20.

Kanmani, P. and J. W. Rhim (2014). "Physicochemical properties of gelatin/silver nanoparticle antimicrobial composite films." Food Chemistry 148: 162-169.

Kargl, R., T. Mohan, et al. (2013). "Functional patterning of biopolymer thin films using enzymes and lithographic methods." Advanced Functional Materials 23(3): 308-315.

Keegstra, K., K. Talmadge, et al. (1973). "The structure of plants cell walls. III. A model of the walls os suspension-cultured sycamore cells based on the interconnections of the macromolecular componenents." Plant Physiology 51: 188-196.

Knez, M., K. Niesch, et al. (2007). "Synthesis and surface engineering of complex nanostructures by atomic layer deposition." Advanced Materials 19(21): 3425-3438.

Koeneman, B. a., Y. Zhang, et al. (2010). "Toxicity and cellular responses of intestinal cells exposed to titanium dioxide." Cell biology and toxicology 26: 225-238.

Kontturi, E., L.-S. Johansson, et al. (2007). "Cellulose nanocrystal submonolayers by spin coating." Langmuir 23(19): 9674-9680.

Kontturi, E., T. Tammelin, et al. (2006). "Cellulose - model films and the fundamental approach." Chemical Society Reviews 35(12): 1287-1304.

Kontturi, E., P. C. Thune, et al. (2005). "Trimethylsilylcellulose/polystyrene blends as a means to construct cellulose domains on cellulose." Macromolecules 38(26): 10712-10720.

Langmuir, I. (1920). "The mechanism of the surface phenomena of flotation." Transactions of the Faraday Society 15(June): 62-74.

Lape, N. K., E. E. Nuxoll, et al. (2004). "Polydisperse flakes in barrier films." Journal of Membrane Science 236: 29-37.

Lee, H. V., S. B. A. Hamid, et al. (2014). "Conversion of lignocellulosic biomass to nanocellulose: structure and chemical process." Thee Scientific World Journal: 1-20. 
Lens, F., A. Tixier, et al. (2013). "Embolism resistance as a key mechanism to understand adaptive plant strategies." Current Opinion in Plant Biology 16(3): 287-292.

Lomer, M. C. E., R. P. H. Thompson, et al. (2000). "Determination of titanium dioxide in foods using inductively coupled plasma optical emission spectrometry." Analyst 125(12): 2339-2343.

MacNicoll, A., M. Kelly, et al. (2015). "A study of the uptake and biodistribution of nano-titanium dioxide using in vitro and in vivo models of oral intake." Journal of Nanoparticle Research 17: 66.

Maisanaba, S., S. Pichardo, et al. (2014). "Cytotoxicity and mutagenicity studies on migration extracts from nanocomposites with potential use in food packaging." Food and Chemical Toxicology 66: 366-372. Martin, C. and B. Jean (2014). "Nanocellulose/polymer multilayered thin films: tunable architectures towards tailored physical properties." Nordic Pulp \& Paper Research Journal 29(1): 19-30.

Mauricio-Iglesias, M., S. Peyron, et al. (2010). "Wheat gluten nanocomposite films as food-contact materials: Migration tests and impact of a novel food stabilization technology (High pressure)." Journal of Applied Polymer Science 116.

McCracken, C., P. K. Dutta, et al. (2016). "Critical assessment of toxicological effects of ingested nanoparticles." Environmental Science: Nano: in press.

Moggridge, G. D., N. K. Lape, et al. (2003). Barrier films using flakes and reactive additives. Progress in Organic Coatings. 46: 231-240.

Moreau, C., N. Beury, et al. (2012). "Tuning the architecture of cellulose nanocrystal-poly(allylamine hydrochloride) multilayered thin films: influence of dipping parameters." Langmuir 28(28): 10425-10436. Moreau, C., V. Villares, et al. (2016). "Tuning supramolecular interactions of cellulose nanocrystals to design innovative functional materials." Industrial Crops and Products In press.

Nasiri, A., S. Peyron, et al. (2016). "Effect of nanoclay on the transfer properties of immanent additives in food packages." Journal of Materials Science $\mathbf{5 1 .}$

Nelson, N. (1944). "A photometric adaptation of the Somogyi method for the determination of glucose." Journal of Biological Chemistry 153: 375-380.

Nielsen, L. E. (1967). "No Title." J. Macromol. Sci., Chem. A1: 929.

Oberdörster, G., A. Maynard, et al. (2005). "Principles for characterizing the potential human health effects from exposure to nanomaterials: elements of a screening strategy." Particle and Fibre Toxicology 2: 1-35.

Ohsaka, T., F. Izumi, et al. (1978). "Raman spectrum of anatase, TiO2." Journal of Raman spectroscopy 7: 321-324.

Olszewska, A. M., E. Kontturi, et al. (2013). "All-cellulose multilayers: long nanofibrils assembled with short nanocrystals." Cellulose 20(4): 1777-1789.

Orts-Gil, G., K. Natte, et al. (2013). "Multi-parametric reference nanomaterials for toxicology: state of the art, future challenges and potential candidates." Rsc Advances 3(40): 18202-18215.

Park, E.-J., G.-H. Lee, et al. (2014). "Time-dependent bioaccumulation of distinct rod-type TiO2

nanoparticles: comparison by crystalline phase." Journal of Applied Toxicology 34: 1265-1270.

Park, Y. B. and D. J. Cosgrove (2012). "A revised architecture of primary cell walls based on

biomechanical changes induced by substrate-specific endoglucanases." Plant Physiology 158(4): 19331943.

Paul, M.-A., C. Delcourt, et al. (2005). "Polylactide/montmorillonite nanocomposites: study of the hydrolytic degradation." Polymer Degradation and Stability 87: 535-542.

Pele, L. C., V. Thoree, et al. (2015). "Pharmaceutical/food grade titanium dioxide particles are absorbed into the bloodstream of human volunteers." Particle and Fibre Toxicology 12.

Peters, R. J. B., G. van Bemmel, et al. (2014). "Characterization of titanium dioxide nanoparticles in food products: analytical methods to define nanoparticles." Journal of Agricultural and Food Chemistry 62(27): 6285-6293.

Picart, C., P. Lavalle, et al. (2001). "Buildup mechanism for poly(l-lysine)/hyaluronic acid films onto a solid surface." Langmuir 17(23): 7414-7424.

Plackett, D., T. L. g. Andersen, et al. (2003). "Biodegradable composites based on L-polylactide and jute fibres." Composites Science and Technology 63: 1287-1296. 
Podsiadlo, P., L. Sui, et al. (2007). "Layer-by-Layer Assembled Films of Cellulose Nanowires with Antireflective Properties." Langmuir 23: 7901-7906.

Powell, J. J., N. Faria, et al. (2010). "Origin and fate of dietary nanoparticles and microparticles in the gastrointestinal tract." Journal of Autoimmunity 34(3): J226-J233.

Richardson, J. J., M. Björnmalm, et al. (2015). "Technology-driven layer-by-layer assembly of nanofilms." Science 348(6233): 411-.

Roy, P. K., M. Hakkarainen, et al. (2012). "Nanoclay effects on the degradation process and product patterns of polylactide." Polymer Degradation and Stability 97: 1254-1260.

Rydström Lundin, C. (2012). Nanoparticles in Food - with a focus on the toxicity of titanium dioxide. Master's thesis, Upsala Universitet.

Salmen, L. (2004). "Micromechanical understanding of the cell-wall structure." Comptes Rendus Biologies 327(9-10): 873-880.

Schmidt, B., V. Katiyar, et al. (2011). "Migration of nanosized layered double hydroxide platelets from polylactide nanocomposite films." Food Additives \& Contaminants: Part A 28: 956-966.

Schuetz, P. and F. Caruso (2002). "Electrostatically assembled fluorescent thin films of rare-earth-doped lanthanum phosphate nanoparticles." Chemistry of Materials 14(11): 4509-4516.

Schwikal, K., T. Heinze, et al. (2011). "Properties of spruce sulfite pulp and birch kraft pulp after sorption of cationic birch xylan." Cellulose 18: 727-737.

Siegrist, M., N. Stampfli, et al. (2008). "Perceived risks and perceived benefits of different nanotechnology foods and nanotechnology food packaging." Appetite 51: 283-290.

Simon, P., Q. Chaudhry, et al. (2008). "Migration of engineered nanoparticles from polymer packaging to food - a physicochemical view." Journal of Food and Nutrition Research 47: 105-113.

Somogyi, M. (1937). "A reagent for the copper-iodometric determination

of very small amount of sugar." Journal of Biological Chemistry 117: 771-776.

Somogyi, M. (1945). "A new reagent for the determination of sugars." Journal of Biological Chemistry 160: 61-68.

Song, H., B. Li, et al. (2011). "Migration of silver from nanosilver-polyethylene composite packaging into food simulants." Food Additives \& Contaminants: Part A 0049: 1-5.

Stiernstedt, J., N. Nordgren, et al. (2006). "Friction and forces between cellulose model surfaces: A comparison." Journal of Colloid and Interface Science 303(1): 117-123.

Tay, C. Y., W. R. Fang, et al. (2014). "Nano-hydroxyapatite and nano-titanium dioxide exhibit different subcellular distribution and apoptotic profile in human oral epithelium." Acs Applied Materials \& Interfaces 6(9): 6248-6256.

Teubl, B. J., G. Leitinger, et al. (2014). "The buccal mucosa as a route for TiO2 nanoparticle uptake." Nanotoxicology 9(2): 253-261.

Teubl, B. J., C. Schimpel, et al. (2015). "Interactions between nano-TiO2 and the oral cavity: Impact of nanomaterial surface hydrophilicity/hydrophobicity." Journal of Hazardous Materials 286: 298-305. Umbreit, T. H., S. Francke-Carroll, et al. (2012). "Tissue distribution and histopathological effects of titanium dioxide nanoparticles after intravenous or subcutaneous injection in mice." Journal of Applied Toxicology 32(5): 350-357.

Valentin, R., C. Cerclier, et al. (2010). "Extensin-pectin multilayered thin film as mimetic model of the primary plant cell wall." Langmuir 26(12): 9891-9898.

Villares, A., H. Bizot, et al. (2017). "Effect of xyloglucan molar mass on its assembly onto the cellulose surface and its enzymatic susceptibility." Carbohydrate Polymers 157: 1105-1112.

Villares, A., C. Moreau, et al. (2015). "Kinetic aspects of the adsorption of xyloglucan onto cellulose nanocrystals." Soft Matter 11(32): 6472-6481.

von Goetz, N., L. Fabricius, et al. (2013). "Migration of silver from commercial plastic food containers and implications for consumer exposure assessment." Food Additives \& Contaminants: Part A 30: 612-620.

Wågberg, L., L. Ödberg, et al. (1988). "Kinetics of adsorption and ion-exchange reactions during adsorption of cationic polyelectrolytes onto cellulosic fibers." Colloids and Surfaces 31: 119-124. Wang, H. F., L. J. Du, et al. (2013). "Progress in the characterization and safety evaluation of engineered inorganic nanomaterials in food." Nanomedicine 8(12): 2007-2025. 
Weir, A., P. Westerhoff, et al. (2012). "Titanium dioxide nanoparticles in food and personal care products." Environmental Science \& Technology 46(4): 2242-2250.

Winter, H. T., C. Cerclier, et al. (2010). "Improved colloidal stability of bacterial cellulose nanocrystal suspensions for the elaboration of spin-coated cellulose-based model surfaces." Biomacromolecules 11(11): 3144-3151.

Yang, Y., K. Doudrick, et al. (2014). "Characterization of food-grade titanium dioxide: the presence of nanosized particles." Environmental Science \& Technology 48(11): 6391-6400.

Zhao, R. H., E. Hallin, et al. (2014). "Intestinal microparticles and inflammatory bowel diseases: incidental or pathogenic?" Inflammatory Bowel Diseases 20(4): 771-775. 
Highlights

- Biobased nanoparticles are efficient building blocks for innovative materials

- Nanoparticles of titanium dioxide are present in the coatings of some sweets

- Nanoparticles impact the suitability of food-contact packaging 